University of Wollongong

Research Online

Faculty of Engineering - Papers (Archive)

Faculty of Engineering and Information

Sciences

January 2005

\title{
Analytical and numerical solutions for a single vertical drain including the effects of vacuum preloading
}

Buddhima Indraratna

University of Wollongong, indra@uow.edu.au

Cholachat Rujikiatkamjorn

University of Wollongong, cholacha@uow.edu.au

lyathurai Sathananthan

University of Wollongong

Follow this and additional works at: https://ro.uow.edu.au/engpapers

Part of the Engineering Commons

https://ro.uow.edu.au/engpapers/189

\section{Recommended Citation}

Indraratna, Buddhima; Rujikiatkamjorn, Cholachat; and Sathananthan, lyathurai: Analytical and numerical solutions for a single vertical drain including the effects of vacuum preloading 2005.

https://ro.uow.edu.au/engpapers/189

Research Online is the open access institutional repository for the University of Wollongong. For further information contact the UOW Library: research-pubs@uow.edu.au 


\section{ANALYTICAL AND NUMERICAL SOLUTIONS FOR A SINGLE VERTICAL DRAIN INCLUDING THE EFFECTS OF VACUUM PRELOADING}

\section{Buddhima Indraratna ${ }^{\dagger}$}

PhD, DIC, MSc (Lond.), FIEAust.,

Professor of Civil Engineering, Faculty of Engineering, University of Wollongong, Wollongong, NSW 2522, Australia

Tel: +61-2-4221-3046; Fax: +61-2-4221-3238

E-mail: indra@uow.edu.au

\section{Cholachat Rujikiatkamjorn}

BEng (Hons), MEng (AIT),

Doctoral Student, Civil Engineering, Faculty of Engineering, University of Wollongong, Wollongong, NSW 2522, Australia

\section{Iyathurai Sathananthan}

BSc (Hons)

Doctoral Student, Civil Engineering, Faculty of Engineering, University of Wollongong, Wollongong, NSW 2522, Australia

${ }^{\dagger}$ Correspondence to: School of Civil Engineering, Faculty of Engineering, University of Wollongong, Wollongong City, NSW 2522, Australia,

E-mail: indra@uow.edu.au

Submitted to: Canadian Geotechnical Journal 


\title{
ANALYTICAL AND NUMERICAL SOLUTIONS FOR A SINGLE VERTICAL DRAIN INCLUDING THE EFFECTS OF VACUUM PRELOADING
}

Buddhima Indraratna, Cholachat Rujikiatkamjorn and Iyathurai Sathananthan

\begin{abstract}
A system of vertical drains combined with vacuum preloading is an effective method to accelerate soil consolidation by promoting radial flow. This study presents the analytical modeling of vertical drains incorporating vacuum preloading in both axisymmetric and plane strain conditions. The effectiveness of the applied vacuum pressure along the drain length is considered. The exact solutions applied on the basis of the unit cell theory are supported by finite element analysis using ABAQUS software. Subsequently, the details of an appropriate matching procedure by transforming permeability and vacuum pressure between axisymmetric and equivalent plane strain conditions is described through analytical and numerical schemes. The effects of the magnitude and distribution of vacuum pressure on soft clay consolidation are examined through average excess pore pressure, consolidation settlement and time analyses. Finally, the practical implications of this study are discussed.
\end{abstract}

Key words: consolidation, finite element method, soft clay, vacuum preloading, vertical drains 


\section{Introduction}

In recent years, the construction of highway and railway embankments over unconsolidated soft soil deposits has resulted in the advancement of soil improvement techniques. To avoid excessive total and differential settlement of highly compressible soil, the application of preloading is regarded as one of the classical and popular methods in practice. Preloading is the application of surcharge load on the site prior to the placement of the permanent structure until most of the primary consolidation is achieved. However, in the case of thick soil deposits with low permeability, the consolidation time by preloading alone is considerably long, hence, a system of vertical drains is often introduced to achieve accelerated radial drainage and consolidation (Nicholson and Jardine 1982). The performance of various types of vertical drains including sand drains, sand compaction piles, prefabricated vertical drains (geosynthetic) and gravel piles have been studied in the past (Richart 1957; Cooper and Rose 1999; Indraratna et al. 1999). The use of prefabricated vertical drains with vacuum application is cost-effective, and also the height of the surcharge embankment can be reduced to achieve the same consolidation settlement (Holtz et al. 1991; Shang et al. 1998). The mechanism of vacuum-assisted consolidation is comparable to, but not the same as conventional surcharge. In earlier studies, vacuum preloading was often simulated with an equivalent surface load or by modifying the surface boundary condition. However, laboratory observations confirm that the vacuum pressure propagates downwards along the drains (trapezoidal distribution) in addition to the uniformly applied surface suction. Indraratna et al. (2004) have also explained this modeling approach in a recently accepted Canadian Geotechnical paper. The rate of 
consolidation attributed to vacuum-assisted preloading is greater than the conventional method because of the increase in the lateral hydraulic gradient.

In order to analyse the behaviour of vertical drains, the unit cell theory representing a single drain surrounded by a soil annulus in axisymmetric condition (3D) was proposed by Barron (1948) and Richart (1957). Subsequently, Hird et al. (1992) introduced a unit cell formulated for the plane strain condition (2D), which can be more conveniently simulated in numerical modeling. For multi-drain simulation, the plane strain finite element analysis can be readily adapted to most field situations (Hansbo 1981; Hansbo 1997; Indraratna and Redana 1997; Indraratna and Redana 2000). Nevertheless, realistic field predictions require the axisymmetric properties to be converted to an equivalent 2D plane strain condition, especially with regard to the permeability coefficients and drain geometry (Indraratna and Redana 1997). The plane strain analysis can also accommodate vacuum preloading in conjunction with vertical drains (e.g. Gabr and Szabo 1997). Mohamedelhassan and Shang (2002) discussed the application of vacuum pressure and its benefits, but without any vertical drains. The simulation of vacuum pressure for the vertical drain system in analytical or numerical models requires further refinement to obtain better predictions in the field.

The main objective of this paper is to introduce comprehensive analytical solutions for vacuum preloading in conjunction with vertical drains, both in the axisymmetric and equivalent plane strain conditions.. The finite element model (ABAQUS, Hibbitt et al. 2004) incorporating these solutions is then validated for the single drain situation. This finite element simulation also gives confidence to the users that a FEM code such as ABAQUS capturing the authors' theoretical formulations can 
then be extended to analyze multi-drain case studies, given the convincing validation for a single drain condition. It is to be noted, however, that demonstrating the ABAQUS application for multi-drain field situations is not within the scope of this paper.

\section{Analytical Solution for Vertical Drain without Vacuum Preloading}

The analytical solutions are based on the equal strain concept and are divided into two categories, namely axisymmetric and plane strain conditions. For a single drain analysis, the effects of well resistance and smear zone are included. Figure 1 illustrates the unit cell adopted for analytical solutions for the axisymmetric and plane strain conditions, respectively.

The main assumptions made in the writers' analysis are summarised below:

- The soil is fully saturated and homogeneous, and laminar flow through the soil (Darcy's law) is adopted. At the outer boundary of the unit cell, flow is not allowed to occur, and for relatively long vertical drains, only the radial (horizontal) flow is permitted to occur.

- For relatively small increments of effective stress $(d \sigma)$, radial consolidation theory (Barron 1948) is followed by a vertical drain installed in saturated clay.

- Based on the equal strain concept (Barron 1948), all vertical strains at any given depth $z$ are assumed to be equal, and compressive strains are allowed to occur in the vertical direction only. The permeability of the soil is assumed to be constant during consolidation. 
The governing equation for radial consolidation (Barron 1948) can be expressed by:

$$
c_{h}\left(\frac{1}{r} \frac{\partial u}{\partial r}+\frac{\partial^{2} u}{\partial r^{2}}\right)=\frac{\partial u}{\partial t}
$$

The definitions of all parameters are given in the list of the Notation.

The solution for the above expression is given by (modified after Hansbo 1981):

$$
\begin{aligned}
\frac{\bar{u}}{\sigma_{1}}= & \exp \left(\frac{-8 T_{h, a x}}{\mu_{a x}}\right) \quad \text { where, } \\
\mu_{a x}= & \frac{n^{2}}{n^{2}-1}\left[\ln \left(\frac{n}{s}\right)+\frac{k_{h, a x}}{k_{s, a x}} \ln (s)-\frac{3}{4}\right]+ \\
& \frac{s^{2}}{n^{2}-1}\left(1-\frac{s^{2}}{4 n^{2}}\right)+\frac{k_{h, a x}}{k_{s, a x}} \frac{1}{n^{2}-1}\left(\frac{s^{4}-1}{4 n^{2}}-s^{2}+1\right)+
\end{aligned}
$$

$[2 \mathrm{~b}]$

$$
\begin{aligned}
& \pi \frac{2 k_{h, a x}}{3 q_{w}} l^{2}\left(1-\frac{1}{n^{2}}\right) \\
\approx & {\left[\ln \left(\frac{n}{s}\right)+\frac{k_{h, a x}}{k_{s, a x}} \ln (s)-\frac{3}{4}+\pi \frac{2 k_{h, a x}}{3 q_{w}} l^{2}\right] }
\end{aligned}
$$

[2c]

$$
T_{h, a x}=c_{h, a x} t / d_{e}^{2}
$$

In the above expressions, $n=d_{e} / d_{w}, s=d_{s} / d_{w}$, and the equivalent diameter of the vertical drain can be calculated by $d_{w}=2(a+b) / \pi$, where $a$ and $b$ are the width and the thickness of the prefabricated vertical drain (PVD), respectively (Hansbo 1981).

\section{Plane strain condition}

The governing equation for conventional radial consolidation is as follows:

$$
c_{h} \frac{\partial^{2} u}{\partial x^{2}}=\frac{\partial u}{\partial t}
$$


The solution for this equation (modified after Indraratna and Redana 2000) is given by:

$$
\frac{\bar{u}}{\sigma_{1}}=\exp \left(\frac{-8 T_{h, p s}}{\mu_{p s}}\right), \quad \text { where }
$$

$$
\mu_{p s}=\left[\alpha+\frac{k_{h, p s}}{k_{s, p s}} \beta+\theta\right]
$$

where, $\quad \alpha=\frac{2}{3} \frac{(n-s)^{3}}{n^{2}(n-1)}$,

$$
\beta=\frac{2(s-1)}{n^{2}(n-1)}\left[n(n-s-1)+\frac{1}{3}\left(s^{2}+s+1\right)\right]
$$

and

$$
\theta=\frac{4 k_{h, p s}}{3 B q_{w, p s}}\left(1-\frac{1}{n}\right) l^{2}
$$

$$
T_{h, p s}=c_{h, p s} t / B^{2}
$$

In the above expressions, $n=B / b_{w}$ and $s=b_{s} / b_{w}$. For plane strain analysis, $B . b_{s}$ and $b_{w}$ are assumed to be equal to $r_{e}, r_{s}$ and $r_{w}$, respectively (also refer to Figure 1).

\section{Analytical Model for Vertical Drain with Vacuum Preloading}

Experience has shown that when vacuum pressure is applied in the field through prefabricated vertical drains (PVDs), the suction head along the drain length may decrease with depth, thereby reducing the efficiency (Chu et al. 2000). In case of the short vertical drains, laboratory measurements at a few points along the drain in the large-scale consolidometer (Figure 2a) clearly indicated that the vacuum pressure not only propagates immediately but also decreases down the drain length. The rate of development of vacuum pressure within the drain may depend on the length and type of PVD (core and filter properties), but some field studies suggest that the vacuum pressure develops rapidly even if the PVD are long (Bo et al., 2003). In order to study 
the effect of vacuum loss, the vacuum pressure distribution along the drain boundary is considered to vary linearly from $-p_{0}$ at top of the drain to $-k_{1} p_{0}$ at the bottom of the drain, where $k_{1}$ is a ratio between vacuum pressure at the bottom and the top of the drain (Figure 2b)

\section{Solution for axisymmetric condition}

The flow rate in the radial direction in the unit cell can be expressed by Darcy's law as:

$$
\frac{\partial Q}{\partial t}=\frac{k}{\gamma_{w}} \frac{\partial u}{\partial r} A
$$

where, $Q$ is the flow in the soil mass, $u$ is the excess pore pressure due to preloading, $A$ is the cross sectional area of the flow at distance $r$ which is equal to $2 \pi r(d z)$.

The rate of change in volume of the soil mass in the vertical direction is given by:

$$
\frac{\partial V}{\partial t}=\frac{\partial \varepsilon}{\partial t} \pi\left(r_{e}^{2}-r^{2}\right) d z
$$

where, $V$ is the volume of the soil mass, and $\varepsilon$ is the vertical strain.

The radial flow rate in the unit cell is assumed to be equal to the rate of volume change of the soil mass in the vertical direction, therefore,

$$
\frac{k}{\gamma_{w}} \frac{\partial u}{\partial r} 2 \pi r(d z)=\frac{\partial \varepsilon}{\partial t} \pi\left(r_{e}^{2}-r^{2}\right) d z
$$

By rearranging Equation (7), the excess pore pressure gradient outside the smear zone can be derived as: 


$$
\frac{\partial u}{\partial r}=\frac{\gamma_{w}}{2 k_{h, a x}} \frac{\partial \varepsilon}{\partial t}\left(\frac{r_{e}^{2}-r^{2}}{r}\right) \quad \text { for } r_{s} \leq r \leq r_{e}
$$

Similarly, in the smear zone, the corresponding pore pressure gradient is given by:

$$
\frac{\partial u_{s}}{\partial r}=\frac{\gamma_{w}}{2 k_{s, a x}} \frac{\partial \varepsilon}{\partial t}\left(\frac{r_{e}^{2}-r^{2}}{r}\right) \quad \text { for } r_{w} \leq r \leq r_{s}
$$

Considering the horizontal cross-sectional slice of thickness $d z$ of a circular cylindrical drain with radius $r_{w}$ (Fig. 2c), the change of flow in the $z$ direction of the drain from the entrance to the exit of the slice $d Q_{z}$ is expressed by:

$$
d Q_{z}=\frac{q_{w}}{\gamma_{w}} \frac{\partial^{2} u}{\partial z^{2}} d z d t \quad \text { for } r \leq r_{w}
$$

The flow term $q_{w}$ represents well resistance. Unless the drains are very large (>20 m), twisted or folded the well resistance of most PVD can generally be neglected (Holtz et al., 1991; Indraratna and Redana, 2000).

The total change in flow from the entrance face to the exit face of the slice is given by:

$$
d Q_{r}=\frac{2 \pi r_{w} k_{s, a x}}{\gamma_{w}} \frac{\partial u}{\partial r} d z d t \quad \text { for } r=r_{w}
$$

If the water is assumed to be incompressible, the following equation should be satisfied:

$$
d Q_{z}+d Q_{r}=0
$$

At the drain boundary $\left(r=r_{w}\right)$, it is assumed that sudden drop in pore pressure does not take place, hence $u=u_{s}$. Substituting Equations (10) and (11) in Equation (12) and subsequent rearranging with the above boundary conditions yields:

$$
\left(\frac{\partial u_{s}}{\partial r}\right)_{r=r_{w}}+\frac{q_{w}}{2 \pi r_{w} k_{s, a x}}\left(\frac{\partial^{2} u_{s}}{\partial z^{2}}\right)_{r=r_{w}}=0
$$


Integrating Equation (13) in the $z$ direction, after substituting Equation (9) into Equation (13), subjects to the following boundary conditions: at $z=0, u_{s}=-p_{0, a x}$ (applied vacuum pressure), and at $z=l, \partial u_{s} / \partial z=p_{0, a x}\left(1-k_{1}\right) / l$, the excess pore pressure at $r=r_{w}$, may be determined by:

$$
\left(u_{s}\right)_{r=r_{w}}=-p_{0, a x}\left(1-\left(1-k_{1}\right) \frac{z}{l}\right)+\frac{\gamma_{w} \pi r_{w}^{2}}{q_{w}} \frac{\partial \varepsilon}{\partial t}\left(n^{2}-1\right)\left(l z-\frac{z^{2}}{2}\right)
$$

Integrating Equations (8) and (9) in the $r$ direction with the boundary conditions given in Equation (14), and by assuming $u_{s}=u$ at the interface $r=r_{s}$ (see Fig. 2c), $u$ and $u_{s}$ can be expressed by:

$$
u_{s}=-p_{0, a x}\left(1-\left(1-k_{1}\right) \frac{z}{l}\right)+\frac{\gamma_{w}}{2 k_{s, a x}} \frac{\partial \varepsilon}{\partial t}\left[\begin{array}{l}
r_{e}^{2} \ln \frac{r}{r_{w}}-\frac{r^{2}-r_{w}^{2}}{2}+ \\
\frac{\pi r_{w}^{2} k_{s, a x}}{q_{w}}\left(n^{2}-1\right)\left(2 l z-z^{2}\right)
\end{array}\right] ; \text { for } r_{w} \leq r \leq r_{s}
$$

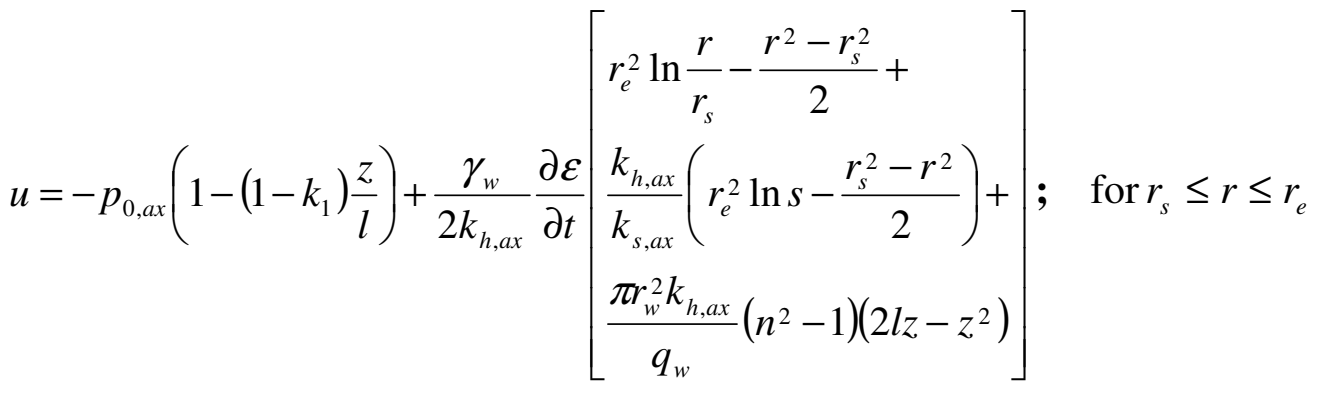

The mean excess pore pressure $(\bar{u})$ is determined from:

$$
\bar{u} \pi\left(r_{e}^{2}-r_{w}^{2}\right) l=\int_{0}^{l} \int_{r_{w}}^{r_{s}} 2 \pi u_{s} r d r d z+\int_{0}^{l} \int_{r_{s}}^{r_{e}} 2 \pi u r d r d z
$$


Integrating Equation (17) after substituting Equations (15) and (16) into Equation (17), the average excess pore pressure is given by:

[18] $\quad \bar{u}=\frac{\gamma_{w}}{2 k_{h, a x}} \frac{\partial \varepsilon}{\partial t} \frac{d_{e}^{2}}{4} \mu_{a x}-\frac{\left(1+k_{1}\right) p_{0, a x}}{2}$

where,

$$
\begin{aligned}
\mu_{a x}= & \frac{n^{2}}{n^{2}-1}\left[\ln \left(\frac{n}{s}\right)+\frac{k_{h, a x}}{k_{s, a x}} \ln (s)-\frac{3}{4}\right]+ \\
& \frac{s^{2}}{n^{2}-1}\left(1-\frac{s^{2}}{4 n^{2}}\right)+\frac{k_{h, a x}}{k_{s, a x}} \frac{1}{n^{2}-1}\left(\frac{s^{4}-1}{4 n^{2}}-s^{2}+1\right)+
\end{aligned}
$$

$$
\begin{aligned}
& \pi \frac{2 k_{h, a x}}{3 q_{w}} l^{2}\left(1-\frac{1}{n^{2}}\right) \\
\approx & {\left[\ln \left(\frac{n}{s}\right)+\frac{k_{h, a x}}{k_{s, a x}} \ln (s)-\frac{3}{4}+\pi \frac{2 k_{h, a x}}{3 q_{w}} l^{2}\right] }
\end{aligned}
$$

If the well resistance is ignored, $\mu_{a x}$ becomes:

$$
\mu_{a x} \approx\left[\ln \left(\frac{n}{s}\right)+\frac{k_{h, a x}}{k_{s, a x}} \ln (s)-\frac{3}{4}\right]
$$

If the well resistance and smear effect are ignored, $\mu_{a x}$ becomes:

$$
\mu_{a x} \approx\left[\ln (n)-\frac{3}{4}\right]
$$

Combining Equation (18) with the well known compressibility relationship $\left(\partial \varepsilon / \partial t=-m_{v} \partial \bar{u} / \partial t\right)$ gives:

$$
\bar{u}=-\frac{\gamma_{w}}{8 k_{h, a x}} m_{v} \frac{\partial \bar{u}}{\partial t} d_{e}^{2} \mu_{a x}-\frac{\left(1+k_{1}\right) p_{0, a x}}{2}
$$


Rearranging the above Equation (19) and then integrating by applying the boundary condition $\bar{u}=\sigma_{1}$ at $t=0$ gives:

$$
\frac{\bar{u}}{\sigma_{1}}=\left(1+\frac{\left(1+k_{1}\right) p_{0, a x}}{2 \sigma_{1}}\right) \exp \left(\frac{-8 T_{h, a x}}{\mu_{a x}}\right)-\frac{\left(1+k_{1}\right) p_{0, a x}}{2 \sigma_{1}}
$$

For the above equation, the vacuum pressure ratio (VPR) can be introduced by the value of $p_{0} / \sigma_{1}$ (i.e. applied vacuum pressure/preloading pressure).

The average degree of consolidation can now be evaluated conveniently by the equation:

$$
U_{h}(\%)=\frac{1-\frac{\bar{u}}{\sigma_{1}}}{1-\frac{\bar{u}_{\infty}}{\sigma_{1}}} \times 100
$$

where, $\frac{\bar{u}_{\infty}}{\sigma_{1}}$ can be calculated by Equation (20) when $t \rightarrow \infty$

For long drains, if the vacuum pressure at the bottom of the drain is assumed to be zero (i.e. $k_{1}=0$ ), Equation (20) becomes:

$$
\frac{\bar{u}}{\sigma_{1}}=\left(1+\frac{p_{0, a x}}{2 \sigma_{1}}\right) \exp \left(\frac{-8 T_{h, a x}}{\mu_{a x}}\right)-\frac{p_{0, a x}}{2 \sigma_{1}}
$$

Solutions for plane strain condition

Since the procedures for plane strain analysis are similar to the axisymmetric condition, the exact solution can be written as (details are given in Appendix A): 


$$
\frac{\bar{u}}{\sigma_{1}}=\left(1+p_{0, p s} \frac{\left(1+k_{1}\right)}{2 \sigma_{1}}\right) \exp \left(\frac{-8 T_{h, p s}}{\mu_{p s}}\right)-\frac{p_{0, p s}}{\sigma_{1}} \frac{\left(1+k_{1}\right)}{2}
$$

where, $\quad \mu_{p s}=\left[\alpha+\frac{k_{h, p s}}{k_{s, p s}}(\beta)+\theta\right], \alpha=\frac{2}{3} \frac{(n-s)^{3}}{n^{2}(n-1)}$,

$$
\beta=\frac{2(s-1)}{n^{2}(n-1)}\left[n(n-s-1)+\frac{1}{3}\left(s^{2}+s+1\right)\right]
$$

and

$$
\theta=\frac{4 k_{h, p s}}{3 B q_{w, p s}}\left(1-\frac{1}{n}\right) l^{2}
$$

Neglecting the well resistance, $\mu_{p s}$ becomes:

$$
\mu_{p s}=\left[\alpha+\frac{k_{h, p s}}{k_{s, p s}}(\beta)\right]
$$

Neglecting both well resistance and smear effect, $\mu_{p s}$ becomes:

$$
\mu_{p s}=\frac{2}{3} \frac{(n-1)^{2}}{n^{2}}
$$

When the vacuum pressure is zero at the bottom of the drain $\left(k_{1}=0\right)$, the exact solution can be expressed by:

$$
\frac{\bar{u}}{\sigma_{1}}=\left(1+\frac{p_{0, p s}}{2 \sigma_{1}}\right) \exp \left(\frac{-8 T_{h, p s}}{\mu_{p s}}\right)-\frac{p_{0, p s}}{2 \sigma_{1}}
$$




\section{Numerical Modeling of Vertical Drain Incorporating Vacuum Preloading}

A finite element program (ABAQUS) was employed to simulate the unit cell of a vertical drain, where an elastic analysis was conducted with $m_{v}=10^{-3} \mathrm{~m}^{2} / \mathrm{kN}$ and with $v=0$ to simulate the condition of zero lateral displacement. The consolidation analysis, based on Biot's solution is used in ABAQUS. In the field, at the embankment centreline (exploiting symmetry), the condition of negligible lateral displacement can be justified. A reconstituted clay from Sydney, Australia was used to conduct large-scale consolidation testing in order to measure the vacuum pressure distribution along the drain. The soil properties were examined using the same large-scale consolidation tests and have been described elsewhere by Indraratna and Redana (1997). The horizontal undisturbed soil permeability $\left(k_{h, a x}\right)$ was determined from 1-D consolidation tests to be appoximately $10^{-10} \mathrm{~m} / \mathrm{s}$. According to Indraratna and Redana (2000), the ratio of the undisturbed permeability to the smear zone permeability $\left(k_{h, a x} / k_{s, a x}\right)$ was assumed to be 3.0. The top, bottom and outer boundaries were set as impermeable (see Figure $3 b$ ). The vertical loading pressure $\left(\sigma_{1}=50 \mathrm{kPa}\right)$ was applied at the top of the cell. The horizontal displacement boundary was fixed (i.e. no movement in the horizontal direction), while vertical displacement was permitted. A vacuum pressure ratio (VPR) of unity was employed (i.e. $p_{0} / \sigma_{1}=1.0$ ). In order to avoid non-uniform settlement (equal strain condition), rigid elements were selected at the soil surface. For the analytical and numerical analysis, the following two cases were examined:

Case A: short drain analysis The dimensions of the unit cell (see Fig. 3) were $450 \mathrm{~mm}$ (i.e. influence zone diameter or the width of the unit cell) and $950 \mathrm{~mm}$ (height). The equivalent drain diameter $\left(d_{w}\right)$ or drain width $\left(2 b_{w}\right)$ was taken to be $50 \mathrm{~mm}$. The smear 
diameter $\left(d_{s}\right)$ or smear zone width $\left(2 b_{s}\right)$ was $170 \mathrm{~mm}$, based on laboratory teating by Indraratna and Redana (1997). A total of 160 elements (8-node bi-quadratic displacement and bilinear pore pressure) were used in the finite element analysis (Figures $3 \mathrm{a}$ and $3 \mathrm{~b}$ ). In the entire finite element mesh, the aspect ratio of elements was kept below 3. To simulate the drain boundary, the pore pressure was either set to zero for the conventional case (no vacuum pressure) or specified to be maximum (negative) at the top, reducing linearly to 75 percent of applied vacuum pressure at the bottom $\left(k_{1}=\right.$ 0.75 ) in agreement with the laboratory results shown in Figure 2a.

Case B: long drain analysis The dimensions of the unit cell and vertical drain were kept the same as Case A. To simulate a long vertical drain, the height of soil was taken to be $10 \mathrm{~m}$, and the vacuum pressure at the bottom of the drain was assumed to be zero. The pore pressure at the drain boundary was set to maximum $\left(-p_{0}\right)$ at the top, reducing linearly to zero at the bottom (Figure 3c).

\section{Validation of Finite Element Model Incorporating the Analytical Solutions}

The analytical solutions developed by the authors including the equivalent plane strain parameters can be readily input via appropriate subroutines in commercial software such as ABAQUS. The results of a finite element (ABAQUS) analysis with and without smear effects are plotted together with the analytical predictions in the form of average excess pore pressure ratios and time. Negligible error between these plots verifies the validity of the finite element model capturing the authors' solution. The predicted average excess pore pressure is calculated using the excess pore pressure values obtained from the finite element analysis. In the following analysis, the discharge capacity $\left(q_{w}\right)$ of the drain is assumed to be high enough for well resistance to be 
neglected. Indraratna and Redana (2000) described that well resistance becomes significant for PVD with $q_{w}$ less than 40-60 $\mathrm{m}^{3} /$ year. First, the results of numerical modeling of a vertical drain without vacuum pressure are validated with the analytical model. Secondly, the analytical and numerical solutions with vacuum pressure are validated.

Vertical drain without vacuum preloading

The comparison of average excess pore water pressure ratio $\left(\bar{u} / \sigma_{1}\right)$ between the analytical model [Equation (2)] and numerical predictions for the axisymmetric condition is shown in Figure 4 . For this study, $c_{h}$ value of $0.32 \mathrm{~m}^{2} / \mathrm{yr}$ obtained from 1D consolidation test and $r_{e}$ of $225 \mathrm{~mm}$ were used for the relationship between time factor $\left(T_{h}\right)$ and time $(t)$, and a good agreement was found. Very small deviations are noted for the range $30<t<200$ days $\left(0.13<T_{h}<0.84\right)$, with a maximum error of about $4 \%$. Figure 5 illustrates the comparison of average excess pore pressure ratio between the analytical model (Equation (4)) and the numerical solution for the plane strain condition. Again, good agreement between the two models could be found, with the difference in results becoming insignificant for $t>10$ days $\left(T_{h}>0.04\right)$.

\section{Vertical drain with vacuum preloading}

Figures 6 and 7 represent the comparison of average excess pore pressure ratio between Cases A and B for axisymmetric and plane strain conditions, respectively. For axisymmetric conditions, the results between the finite element and analytical models (Equation (20) for Case A and Equation (22) for Case B) are in good agreement (Figure 6). For plane strain conditions (Figure 7), the results from the analytical solution (i.e. 
Equation (23) for Case A and Equation (24) for Case B) agree well with those from the numerical solutions for the entire range of time with the maximum deviation observed around 10 days for smear effect (i.e. $T_{h} \approx 0.04$ ). For axisymmetric conditions (Figure 6), the difference in average excess pore pressure ratio between Case A (25\% vacuum loss with depth) and Case B (vacuum pressure linearly decreasing with depth to zero at the bottom of the drain) becomes considerable after about 90 days and 30 days for drain with and without smear, respectively, when the average excess pore pressures of Case A start to become negative. For the plane strain condition (Figure 7), the deviation between Case A and Case B is significant after 30days (with smear) and 20 days (ideal drain), where the average excess pore pressure ratio for Case $\mathrm{B}$ is less negative in contrast to Case A. Both Figures 6 and 7 confirm that the ultimate negative average excess pore pressure ratios for Case A (approximately 0.90) are markedly different to that of Case B (0.50). As discussed later, this also corresponds to a greater ultimate settlement associated with Case A as compared to Case B.

\section{Comparison between Axisymmetric and Equivalent Plane Strain Analyses}

In general, the conversion procedure used in vertical drain modeling (Hird et al. 1992, Indraratna and Redana 1997, Indraratna and Redana 2000) is useful in transforming parameters from the true axisymmetric condition (3D) to the equivalent plane strain condition conveniently employed in 2D finite element analyses. In this section, only smear effect is considered in the analysis. The differences between the axisymmetric and plane strain conditions (prior to conversion) with and without vacuum preloading are shown in Figures 8 and 9, respectively. For the conventional surcharge loading with no vacuum pressure (Figure 8), the comparison between the axisymmetric and plane 
strain conditions confirms that the dissipation of average excess pore pressure for the former is slower than the latter. This is because in the unit cell, the flow contact area of a drain wall is greater than a drain well as shown in Figure 1. Figure 8 also shows that the final average excess pore pressure becomes zero after 200 days $\left(T_{h} \approx 0.8\right)$ for plane strain, but for time approaching 500 days in the axisymmetric condition $\left(T_{h} \approx 2.14\right)$. Figures $9 \mathrm{a}$ and $9 \mathrm{~b}$ illustrate the effect of different vacuum pressure distributions (Case $\mathrm{A}$ and Case B), where the plane strain model gives the greater dissipation of average excess pore pressure in comparison with the axisymmetric condition at any given time. As expected, the $25 \%$ vacuum loss along the drain (Case A) shows a greater average excess pore pressure dissipation rate than the $100 \%$ vacuum loss along the drain (Case B).

Figures 8 and 9 demonstrate that the axisymmetric and plane strain solutions can not produce the same consolidation response. Therefore, in order to use a plane strain solution for vertical drains and still obtain the same consolidation as the true axisymmetric condition, one must employ a conversion procedure to derive an equivalent plane strain solution that provides a very good match to the axisymmetric consolidation curve. An equivalent plane strain solution can be obtained either by geometric transformation or permeability transformation or both to minimise the disparity between the two methods (Hird et al. 1992; Indraratna and Redana 1997; Indraratna and Redana 2000). For vacuum preloading, the proposed 'conversion' procedures can be based on the equivalent average excess pore pressure and the equivalent vacuum pressure by still maintaining the geometric equivalence (i.e. $d_{w}=2 b_{w}$, $d_{s}=2 b_{s}, \quad d_{e}=2 B$, in Figure 1). In this study, permeability and vacuum pressure relationships between the axisymmetric and equivalent plane strain conditions have 
been derived by extending the previous theory developed by Indraratna and Redana (1997) and are explained below.

At a given stress level and at each time step, the average excess pore pressure for both axisymmetric and plane strain conditions are made equal by equating Equation (20) with Equation (23). The equivalent permeability and equivalent applied vacuum pressure for the equivalent plane strain condition can now be expressed below:

The equivalent permeability under plane strain is given by:

$$
\frac{k_{h, p s}}{k_{h, a x}}=\frac{\left[\alpha+\frac{k_{h, p s}}{k_{s, p s}}(\beta)+\theta\right]}{\left[\ln \left(\frac{n}{s}\right)+\frac{k_{h, a x}}{k_{s, a x}} \ln (s)-\frac{3}{4}+\pi \frac{2 k_{h, a x}}{3 q_{w}} l^{2}\right]}
$$

Neglecting the well resistance in Equation (25), the ratio of the smear zone permeability to the undisturbed zone permeability is as follows:

$$
\frac{k_{s, p s}}{k_{h, p s}}=\frac{\beta}{\frac{k_{h, p s}}{k_{h, a x}}\left[\ln \left(\frac{n}{s}\right)+\frac{k_{h, a x}}{k_{s, a x}} \ln (s)-\frac{3}{4}\right]-\alpha}
$$

Ignoring, both smear and well resistance effects, the simplified ratio of equivalent plane strain permeability to axisymmetric permeability in the undisturbed zone can be obtained:

$$
\frac{k_{h, p s}}{k_{h, a x}}=\frac{\frac{2}{3} \frac{(n-1)^{2}}{n^{2}}}{[\ln (n)-0.75]}
$$

The equivalent vacuum pressure can be determined by: 
In order to examine the validity of the above conversion procedure, the analytical and numerical models were employed to compare the deviations between the axisymmetric and equivalent plane strain conditions. Based on Equations. (26) to (28), Table 1 shows the parameters used in the axisymmetric and equivalent plane strain conditions for both short and long drain analyses (i.e. Case A and Case B).

After conversion of the original plane strain condition to the equivalent plane strain condition, the results are identical as shown in Figures 10(a) and 10(b). Figure 10(b) illustrates the corresponding finite element simulations which also indicate very similar results. Comparison of Figures 10 (a) and 10(b) confirms that the results of finite element and analytical models almost coincide, hence, for the purpose of clarity, the analytical results and finite element results are plotted separately. Figure 11 compares the results of the analytical and numerical models after application of the permeability and vacuum pressure conversions for both Cases A and B. The analytical plane strain and analytical axisymmetric models give identical results, while the finite element models show a very small discrepancy. In general, the above matching procedure confirms the reliability of the equivalent plane strain model for both Cases A and B.

\section{Effect of Magnitude and Distribution of Vacuum Pressure}

In this section, the effects of the magnitude of vacuum pressure and the distribution of vacuum pressure along the vertical drain are discussed, based on the equivalent plane strain condition. The comparison of settlement between analytical and numerical models with variation of VPR for both Cases A and B is shown in Figures 12(a) and 12(b), 
respectively (Equation (23) to (28)). Almost identical results between the two approaches were found. As expected, the rate of settlement with applied vacuum pressure was faster than conventional loading (surcharge only) without vacuum pressure.

Figure 12 also shows that, at the higher VPR, the rate of settlement and the final settlement are increased. Clearly, the application of vacuum pressure increases the lateral pore pressure gradient, thus promoting radial flow. The accelerated consolidation increases the rate of settlement as well as the ultimate settlement, which is analogous to increasing the applied surcharge load. The consideration of varying vacuum pressure along the length of drain is more realistic, as the effect of vacuum usually diminishes with depth. In other words, for long vertical drains, it is possible that the applied vacuum pressure at the drain top may not be propagated towards the bottom part of the drain. The results plotted in Figure 12 show that the rate of consolidation for $25 \%$ vacuum loss (Case A) is more rapid in comparison with Case B. Also, it is clear that the greater the magnitude of vacuum pressure ratio, the higher the rate of consolidation, but unless the magnitude of vacuum pressure is large enough (e.g. VPR > 0.25), the effect on excess pore pressure dissipation may not be significant in practice.

\section{Practical Implications}

The effectiveness of a vertical drain incorporating vacuum pressure does not only depend on the magnitude of the applied vacuum pressure but also on the vacuum pressure ratio. As mentioned previously, if the VPR is small (less than 0.25), the effect of vacuum preloading may not be significant. In the successful field applications, the applied vacuum pressure ratio has been as high as 1 to 2 (e.g. in Tianjin project (Chu et al. 2000) and Yaoqiang Airport (Tang and Shang 2000)). With regard to the distribution 
of applied vacuum pressure, the almost constant vacuum pressure with depth may be used to predict the field behavior of short vertical drains (say less than $10 \mathrm{~m}$ ). In the case of long vertical drains (exceeding $10 \mathrm{~m}$ ), Chu et al. (2000) demonstrated that by applying a vacuum pressure, the reduction in the excess pore water pressure decreases with depth. This indicates that the diminishing vacuum pressure with depth (assumed linear) is a simplified and useful approach for predicting the performance of long vertical drains.

Most finite element analyses on soft clay embankments are conducted based on the 2D plane strain assumption. Although the consolidation around vertical drains is axisymmetric, in the case of multi-drain analysis of large projects, plane strain analysis is certainly more efficient in a computational point of view when even the most sophisticated powerful finite element codes fail to handle a large number of vertical drains each having its own independent axisymmetric zone. Various researchers have described the advantages of such 2-D plane strain solutions for field studies where a large number of drains are installed, for which a 3D analysis becomes cumbersome and often impractical (e.g. Hird et al. 1992; Chai et al. 1995; Indraratna et al., 1997; Bo et al. 2003).

Figure 13 illustrates the variation of the normalized settlement $\left(S_{\text {vac }} / S_{\text {novac }}\right)$ vs time factor $\left(T_{h, p s}\right)$ relationships with increasing VPR and $n$ values for both Cases A and B (equivalent plane strain) for an ideal drain. The smear effect with a typical value of $s=3$ and $k_{h} / k_{s}=3-5$ is included in Figs. 14 and 15 based on the authors experience. Normalized settlement is defined as the ratio of settlement with vacuum pressure $\left(S_{v a c}\right)$ divided by the settlement without vacuum pressure $\left(S_{\text {novac }}\right)$. Axisymmetric results are 
not plotted in Figures 13-15, because they provide almost identical results to the equivalent plane strain condition. It is shown that unless the VPR values exceed 0.25 , the additional consolidation due to vacuum preloading application may not be significant. In the field, $V P R \geq 1.0$ and $n<20$ will give considerably enhanced settlement (Tang and Shang 2000) as also supported by analytical results shown in Figures 13-15. In summary, useful curves for normalized settlement for a given soil can be developed for an array of VPR and $n$ values similar to the above analysis, which will be most beneficial for design engineers.

\section{Conclusions}

A system of vertical drains combined with vacuum preloading is an effective method for accelerating soil consolidation. In this study, an analytical model for a vertical drain (unit cell) incorporating vacuum preloading as well as smear and well resistance was developed for both axisymmetric and equivalent plane strain conditions. A finite element code (ABAQUS) was employed to analyse the unit cell and to compare the numerical results with the writers' analytical approach. These comparisons confirmed the accuracy of the analytical formulations. A conversion procedure based on the transformation of permeability and vacuum pressure was also introduced to establish the relationships between the axisymmetric (3D) and equivalent plane strain (2D) conditions. Analytical and numerical schemes verified that the equivalent plane strain adaptation is as accurate as the conventional axisymmetric case, hence its adoption in practice can be justified.

In this paper, two different vacuum pressure distributions along a single drain were compared and discussed (i.e. for short drain and long drain). The simulation of varying vacuum pressure along the length of drain is considered to be realistic because 
the applied vacuum pressure at the drain top may not always propagate towards the bottom part of the drain. In the field, this is probably true for the majority of long prefabricated vertical drains installed in soft clay as indicated by past field studies. However, in the case of relatively short vertical drains (say less than $10 \mathrm{~m}$ ), the approximation of constant vacuum pressure with depth may be justified. In practice, the effectiveness of vacuum preloading in soft clay depends on the magnitude of the applied vacuum pressure ratio as well as its actual distribution along the drain length. It is noted from the findings of this study that, if the vacuum pressure ratio (VPR) is less than 0.25 , the effect of vacuum preloading on the excess pore pressure dissipation hence additional settlement is not significant. Moreover, for the same VPR, the rate of settlement in the case of short drains case is greater than that of long drains. Finally, a typical chart for normalized settlement against time factor for various VPR and $n$ values was plotted, which provides a useful preliminary design guide for practicing engineers. Such charts may be produced for an array of VPR and $n$ values, for either constant or varying vacuum pressure distributions with depth. 


\section{Appendix A. Complete details of analytical formulation of vacuum preloading for plane strain condition}

The horizontal flow rate in unit cell can be expressed by Darcy's law as:

$$
\frac{\partial Q}{\partial t}=\frac{k}{\gamma_{w}} \frac{\partial u}{\partial x} d z
$$

where $A$ is cross sectional area of the flow at distance $x$ which is equal to $d z$ (the thickness of the unit cell for plane strain conditions is unity)

The rate of changing volume of soil mass is:

$$
\frac{\partial V}{\partial t}=\frac{\partial \varepsilon}{\partial t}(B-x) d z
$$

The radial flow rate in the unit cell is equal to the rate of volume change of soil mass in the vertical direction therefore,

$$
\frac{k_{h, p s}}{\gamma_{w}} \frac{\partial u}{\partial x} d z=\frac{\partial \varepsilon}{\partial t}(B-x) d z
$$

Rearranging Equation (A.3), the excess pore pressure gradient outside the smear zone can be given by:

$$
\frac{\partial u}{\partial x}=\frac{\gamma_{w}}{k_{h, p s}} \frac{\partial \varepsilon}{\partial t}(B-x) \quad \text { for } b_{s} \leq x \leq B
$$

The corresponding pore pressure gradient in the smear zone is derived as:

$$
\frac{\partial u_{s}}{\partial x}=\frac{\gamma_{w}}{k_{s, p s}} \frac{\partial \varepsilon}{\partial t}(B-x) \quad \text { for } b_{w} \leq x \leq b_{s}
$$

Considering the horizontal cross-sectional slice of thickness $d z$ (Fig. 2c), the change of flow in the $z$ direction of the drain from the entrance to the exit of the slice $d Q_{z}$ is expressed by:

$$
d Q_{z}=\frac{q_{w, p s}}{\gamma_{w}} \frac{\partial^{2} u}{\partial z^{2}} d z d t \text { for } x \leq b_{w}
$$

The horizontal inflow to the drain from each slide $d Q_{x}$ is given by:

$$
d Q_{x}=\frac{k_{s, p s}}{\gamma_{w}} \frac{\partial u}{\partial x} d z d t \quad \text { for } x=b_{w}
$$

If the water is assumed to be incompressible, the following equation should be satisfied: 


$$
d Q_{z}+2 d Q_{x}=0
$$

At the drain boundary $\left(x=b_{w}\right)$, the sudden drop in pore pressure does not take place, hence $u=u_{s}$. Substituting Equations (A.6) and (A.7) in Equation (A.8) and following by rearranging with the above boundary condition yields:

$$
\left(\frac{q_{w, p s}}{2 k_{s, p s}} \frac{\partial^{2} u_{s}}{\partial z^{2}}\right)_{x=b_{w}}+\left(\frac{\partial u_{s}}{\partial x}\right)_{x=b_{w}}=0
$$

Integrating Equation (A.9) in the $z$ direction subjects to the following boundary conditions: at $z=0, u_{s}=-p_{0, p l}$ (applied vacuum pressure), and at $z=l$, $\partial u_{s} / \partial z=p_{0, p l}\left(1-k_{1}\right) / l$, the excess pore pressure at $x=b_{w}$ after substituting Equation (A.5) into Equation (A.9), may be determined by:

$$
\left(u_{s}\right)_{x=b_{w}}=-p_{0, a x}\left(1-\left(1-k_{1}\right) \frac{z}{l}\right)+\frac{2\left(B-b_{w}\right) \gamma_{w}}{q_{w, p s}} \frac{\partial \varepsilon}{\partial t}\left(l z-\frac{z^{2}}{2}\right)
$$

Integrating Equations (A.4) and (A.5) in the $x$ direction with the boundary conditions given in Equation (A.10), and by assuming $u_{s}=u$ at the interface $x=b_{s}$ (see Fig. 2c), $u$ and $u_{s}$ can be expressed by:

[A.11]

$$
\begin{aligned}
u & =\frac{\gamma_{w}}{2 k_{s, p s}} \frac{\partial \varepsilon}{\partial t}\left(\begin{array}{l}
x(2 B-x)+ \\
\frac{2\left(B-b_{w}\right) k_{s, p s}}{q_{w, p s}}\left(2 l z-z^{2}\right)- \\
b_{w}\left(2 B-b_{w}\right)
\end{array}\right)-p_{0, p s}\left[1-\left(1-k_{1}\right) \frac{z}{l}\right] \text { for } b_{w} \leq x \leq b_{s} \\
u & =\frac{\gamma_{w}}{2} \frac{\partial \varepsilon}{\partial t} \frac{1}{k_{h, p s}}\left[\begin{array}{l}
x(2 B-x)+\frac{2\left(B-b_{w}\right)}{q_{w, p s}} k_{h, p s}\left(2 l z-z^{2}\right)- \\
b_{s}\left(2 B-b_{s}\right)+\frac{k_{h, p s}}{k_{s, p s}}\left(b_{s}-b_{w}\right)\left(2 B-b_{s}-b_{w}\right)
\end{array}\right] \text { for } b_{s} \leq x \leq B \\
& -p_{0, p s}\left[1-\left(1-k_{1}\right) \frac{z}{l}\right]
\end{aligned}
$$

The mean excess pore pressure $(\bar{u})$ is determined from:

$$
\bar{u}\left(B-b_{w}\right) l=\int_{0}^{l} \int_{b_{w}}^{b_{s}} u_{s} d x d z+\int_{0}^{l} \int_{b_{s}}^{\mathbf{B}} u d x d z
$$

After substituting Equations (A.11) and (A.12) into Equation (A.13), integrating Equation (A.13), the average excess pore pressure is given by: 
[A.14] $\bar{u}=\frac{B^{2} \gamma_{w}}{2 k_{h, p s}} \frac{\partial \varepsilon}{\partial t} \mu_{p s}-p_{0, p s}\left[\frac{\left(1+k_{1}\right)}{2}\right]$

where, $\quad \mu_{p s}=\left[\alpha+\frac{k_{h, p s}}{k_{s, p s}}(\beta)+\theta\right], \alpha=\frac{2}{3} \frac{(n-s)^{3}}{n^{2}(n-1)}$,

$$
\beta=\frac{2(s-1)}{n^{2}(n-1)}\left[n(n-s-1)+\frac{1}{3}\left(s^{2}+s+1\right)\right]
$$

and $\quad \theta=\frac{4 k_{h, p s}}{3 B q_{w, p s}}\left(1-\frac{1}{n}\right) l^{2}$

Combining Eqaution (A.14) with the well known compressibility relationship $\left(\partial \varepsilon / \partial t=-m_{v} \partial \bar{u} / \partial t\right)$ gives:

[A.15] $\quad \bar{u}=-\frac{\gamma_{w}}{2 k_{h, p s}} m_{v} \frac{\partial \bar{u}}{\partial t} B^{2} \mu_{p s}-p_{0, p s}\left[\frac{\left(1+k_{1}\right)}{2}\right]$

Rearranging Equation (A.15) and then integrating by applying the boundary condition $\bar{u}=\sigma_{1}$ at $t=0$ gives:

[A.16]

$$
\frac{\bar{u}}{\sigma_{1}}=\left(1+p_{0, p s} \frac{\left(1+k_{1}\right)}{2 \sigma_{1}}\right) \exp \left(\frac{-8 T_{h, p s}}{\mu_{p s}}\right)-p_{0, p s} \frac{\left(1+k_{1}\right)}{2 \sigma_{1}}
$$




\section{References}

Barron R.A. 1948. Consolidation of fine-grained soils by drain wells. Transactions, ASCE, 113: 718-754.

Bo, M.W., Chu, J., Low, B.K. and Choa, V. 2003. Soil improvement; prefabricated vertical drain techniques. Thomson Learning, Singapore, 341 p.

Chai, J. C., Miura, N., Sakajo, S., and Bergado, D. 1995. Behavior of vertical drain improved subsoil under embankment loading. J. Soil and Foundations, Japanese Geotechnical Society, 35(4): 49-61.

Chu J., Yan W., and Yang H. 2000. Soil improvement by the vacuum preloading method for an oil storage station. Geotechnique, 50(6): 625-632.

Cooper M.R., and Rose A.N. 1999. Stone column support for an embankment on deep alluvial soils. Proceedings of the Institution of Civil Engineers Geotechnical Engineering, 137(1): 15-25.

Gabr M.A., and Szabo D.J. 1997. Prefabricted vertical drains zone of influence under vacuum in clayey soil. Proceedings of the Conference on In Situ Remediation of the Geoenvironment, ASCE, 449-460.

Hansbo S. 1981. Consolidation of fine-grained soils by prefabricated drains and lime column installation. Proceedings of $10^{\text {th }}$ International Conference on Soil Mechanics and Foundation Engineering, Balkema (Rotterdam) 3: 677-682.

Hansbo S. 1997. Aspects of vertical drain design: Darcian or non-Darcian flow. Geotechnique, 47(5): 983-992. 
Hird C.C., Pyrah I.C., and Russel D. 1992. Finite element modeling of vertical drains beneath embankments on soft ground. Geotechnique, 42(3): 499-511.

Hibbitt, Karlsson, and Sorensen 2004 ABAQUS/Standard User's Manual, Published by HKS Inc.

Holtz R.D., Jamiolkowski M.B., Lancellotta R., and Pedroni R. 1991. Prefabricated Vertical Drains: Design and Performance. CIRIA: London; 1-131.

Indraratna, B., Balasubramaniam, A. S., and Sivaneswaran, N. 1997. Analysis of settlement and lateral deformation of soft clay foundation beneath two full-scale embankments. International Journal for Numerical and Analytical Methods in Geomechanics, 21: 599-618.

Indraratna, B., Bamunawita, C., and Khabbaz, H., 2004. Numerical modeling of vacuum preloading and field applications. Canadian Geotechechnical Journal, 41: 10981110.

Indraratna B., Redana I.W., and Balasubramanium A.S. 1999. Settlement prediction of embankments stabilised with prefabicated vertical drains at Second Bangkok International Airport. Geotechnical Engineering for Transportation Infrastrustucture, Balkama (Rotterdam) 1-7.

Indraratna B., and Redana I.W. 1997. Plane strain modeling of smear effects associated with vertical drains, Journal of Geotechnical and Geoenvironmental Engineering, ASCE, 123(5): 474-478. 
Indraratna B., and Redana I.W. 2000. Numerical modeling of vertical drains with smear and well resistance installed in soft clay. Canadian Geotechnical Journal, 37: $133-145$.

Mohamedelhassan E., and Shang, J.Q. 2002. Vacuum and surcharge combined onedimensional consolidation of clay soils, Canadian Geotechnical Journal, 39: 1126-1138.

Nicholson D.P., and Jardine R.J. 1982. Performance of vertical drains at Queenborough bypass. Vertical Drains, the Institution of Civil Engineers: London, 67-90.

Richart F.E. 1957. A review of the theories for sand drains. Journal of the Soil Mechanics and Foundations Division, ASCE, 83(3): 1-38.

Shang J.Q., Tang M., and Miao Z. 1998. Vacuum preloading consolidation of reclaimed land: a case study. Canadian Geotechnical Journal, 35: 740-749.

Tang, M., and Shang J.Q. 2000. Vacuum preloading consolidation of Yaoqiang Airport runway. Geotechnique, 50(6): 613-623. 


\section{Notation}

B

$b$

$b_{w}$

$c_{h}$

$d$

$d_{e}$

h

$i$.

$k$

$k_{h}$

$k_{s}$

$k_{1}$

$l$

$m_{v}$

n

$p_{0}$

$q_{w}$

$Q$

$r$

$r_{e}$

$r_{w}$ cross-sectional area corresponding to flow $\left(\mathrm{m}^{2}\right)$

width of the prefabricated vertical drain (m)

half width of plane strain unit cell (m)

thickness of the prefabricated vertical drain (m)

half width of drain wall (m)

coefficient of consolidation for horizontal drainage, $c_{h}=k_{h} / \gamma_{w} m_{v}\left(\mathrm{~m}^{2} / \mathrm{s}\right)$

drain spacing $(\mathrm{m})$

diameter of influence zone (m)

hydraulic head (m)

dimensionless hydraulic gradient

permeability coefficient of soil $(\mathrm{m} / \mathrm{s})$

horizontal permeability coefficient in undisturbed zone $(\mathrm{m} / \mathrm{s})$

horizontal permeability coefficient in smear zone $(\mathrm{m} / \mathrm{s})$

ratio between vacuum pressure at the bottom and at the top of vertical drain

length of drain (m)

coefficient of volume compressibility for one-dimensional compression $\left(\mathrm{m}^{2} / \mathrm{kN}\right)$

ratio $r_{e} / r_{w}$ in axisymmetric condition or $B / b_{w}$ in plane strain condition

applied vacuum pressure at the top of the drain $\left(\mathrm{kN} / \mathrm{m}^{2}\right)$

well discharge capacity $\left(\mathrm{m}^{3} / \mathrm{s}\right)$

flow in unit cell $\left(\mathrm{m}^{3}\right)$

distance from center of the drain in axisymmetric unit cell (m)

radius of influence zone (m)

radius of drain well $(\mathrm{m})$ 
Settlement (m)

$S_{\text {vac }} \quad$ Settlement due to surcharge with vacuum preloading (m)

$S_{\text {novac }} \quad$ Final settlement due to surcharge preloading only (m)

$T_{h} \quad$ dimensionless time factor for horizontal drainage, $T_{h, a x}=\frac{c_{h} t}{d_{e}^{2}}$ or $T_{h, p s}=\frac{c_{h} t}{4 B^{2}}$

$t \quad$ time (s, days)

$U_{h} \quad$ average degree of consolidation

$u$ excess pore water pressure $\left(\mathrm{kN} / \mathrm{m}^{2}\right)$

$\bar{u} \quad$ average excess pore water pressure for the unit cell $\left(\mathrm{kN} / \mathrm{m}^{2}\right)$

$\bar{u}_{\infty} \quad$ average applied vacuum pressure for the unit cell $\left(\mathrm{kN} / \mathrm{m}^{2}\right)$

VPR vacuum pressure ratio, $\mathrm{VPR}=p_{0} / \sigma_{1}$

$V \quad$ volume of soil mass $\left(\mathrm{m}^{3}\right)$

$v_{r} \quad$ velocity of flow (at radius $\left.r\right)(\mathrm{m} / \mathrm{s})$

$v_{x} \quad$ velocity of flow (at distance $\left.x\right)(\mathrm{m} / \mathrm{s})$

$x \quad$ distance from center of the drain in plane strain unit cell (m)

$z \quad$ depth (m)

Greek Letters

$\gamma_{\mathrm{w}} \quad$ unit weight of water $\left(\mathrm{kN} / \mathrm{m}^{3}\right)$

$\varepsilon \quad$ vertical strain

$\mu_{a x} \quad$ a group of parameters representing the geometry of the vertical drain system including well resistance and smear effect in the axisymmetric condition

$\mu_{p s} \quad$ a group of parameters representing the geometry of the vertical drain system including well resistance and smear effect in the plane strain condition

$v \quad$ Poisson's ratio in terms of effective stress

$\sigma_{1} \quad$ initial overburden pressure due to preloading $\left(\mathrm{kN} / \mathrm{m}^{2}\right)$

$\quad \quad$ effective stress $\left(\mathrm{kN} / \mathrm{m}^{2}\right)$ 


\section{Subscripts}

$a x$

axisymmetric condition

ps

plane strain condition

s

smear zone 


\section{List of Figures}

Figure 1. Conversion of axisymmetry radial flow adopted for analytical solutions, (a) vertical drain installation layout, (b) vertical drain in plane strain model, (c) axisymmetric unit cell, (d) plane strain unit cell.

Figure 2. (a) Distributions of measured negative pore water pressure along drain boundary in laboratory testing, (b) Distributions of vacuum pressure in analytical model, (c) Vertical cross section of unit cell showing flow condition in vertical drain.

Figure 3. Finite element discretization for axisymmetric and plane strain analyses of soil in unit cell, (a) nodes and integration points for a single 8-node biquadratic displacement, bilinear pore pressure element; (b) Mesh discretization and vacuum pressure distribution for short drain analysis (Case A), (c) mesh discretization and vacuum pressure distribution for long drain analysis (Case B)

Figure 4. Finite element and analytical model results for axisymmetric condition.

Figure 5. Finite element and analytical model results for plane strain condition.

Figure 6. Finite element and analytical model results (axisymmetric with vacuum preloading), (a) Case A: short drain analysis, (b) Case B: long drain analysis.

Figure 7. Finite element and analytical model results (plane strain with vacuum preloading), (a) Case A: short drain analysis, (b) Case B: long drain analysis.

Figure 8. Difference between original axisymmetric and plane strain analyses prior to establishing the equivalent plane strain conversion with smear effect.

Figure 9. Difference between axisymmetric and plane strain analyses prior to establishing the equivalent plane strain conversion, (a) Case A: short drain, (b) Case B: long drain.

Figure 10. Comparison of axisymmetric model with the equivalent plane strain model including smear effect (a) analytical method, (b) FEM.

Figure 11. Comparison of analytical and FEM solutions after conversion to equivalent plane strain condition including smear effect, (a) Case A, analytical method, (b) Case A, FEM; (c) Case B, analytical method; (d) Case B, FEM.

Figure 12. Settlement results from analytical and FEM solutions after conversion to equivalent plane strain condition, (a) Case A, short drain, (b) Case B, long drain.

Figure 13. Normalized settlement-time factor curves for varying $\mathrm{n}$ and VPR values based on the equivalent plane strain solution for ideal condition.

Figure 14. Normalized settlement-time factor curves for varying $\mathrm{n}$ and VPR values based on the equivalent plane strain solution for $s=3 k_{h} / k_{s}=3$.

Figure 15. Normalized settlement-time factor curves for varying $\mathrm{n}$ and VPR values based on the equivalent plane strain solution for $s=3 k_{h} / k_{s}=5$. 
Table 1. Permeability coefficient and vacuum pressure values for axisymmetric and equivalent plane strain conditions

\begin{tabular}{c|cc}
\hline \hline Conversion parameters & Axisymmetric & Equivalent plane strain \\
\hline \hline $\begin{array}{c}\text { Undisturbed horizontal } \\
\text { permeability }\left(k_{h} \times 10^{-10} \mathrm{~m} / \mathrm{s}\right)\end{array}$ & 1.00 & 0.36 \\
$\begin{array}{r}\text { (Eq. 27) } \\
\mathrm{m} / \mathrm{s})\end{array}$ & 0.33 & 0.10 \\
$\begin{array}{r}\text { Smear permeability }\left(k_{s} \times 10^{-10}\right. \\
\text { Vacuum pressure }(\times 100 \mathrm{kPa})\end{array}$ & 0.50 & (Eq. 26) \\
& & 0.50 \\
\hline \hline
\end{tabular}




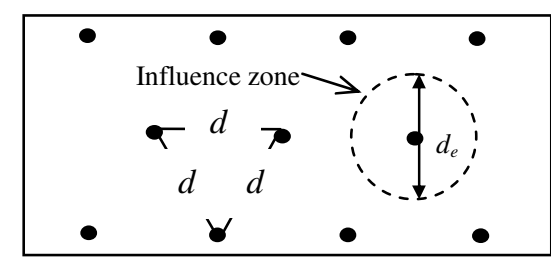

(a)

Flow contact area $=\pi d_{w} l$

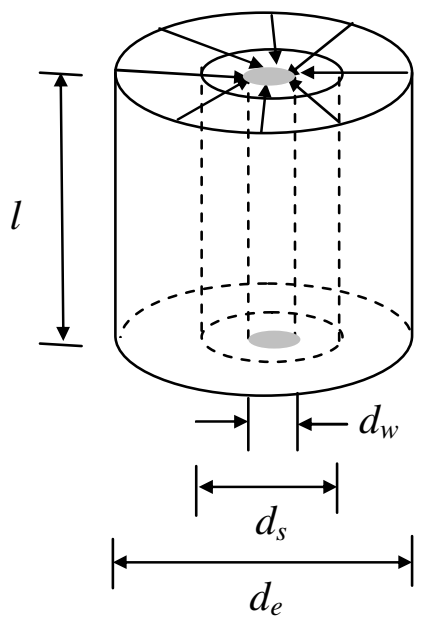

(c)

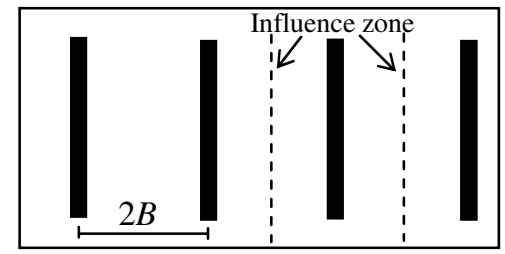

(b)

Flow contact area $=2 l$

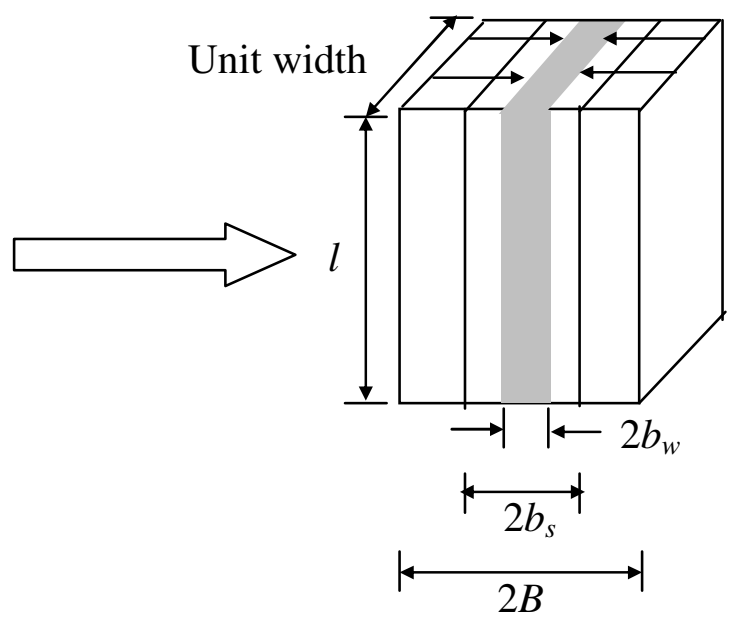

(d)

Figure 1. Conversion of axisymmetry radial flow adopted for analytical solutions, (a) vertical drain installation layout, (b) vertical drain in plane strain model, (c) axisymmetric unit cell, (d) plane strain unit cell. 

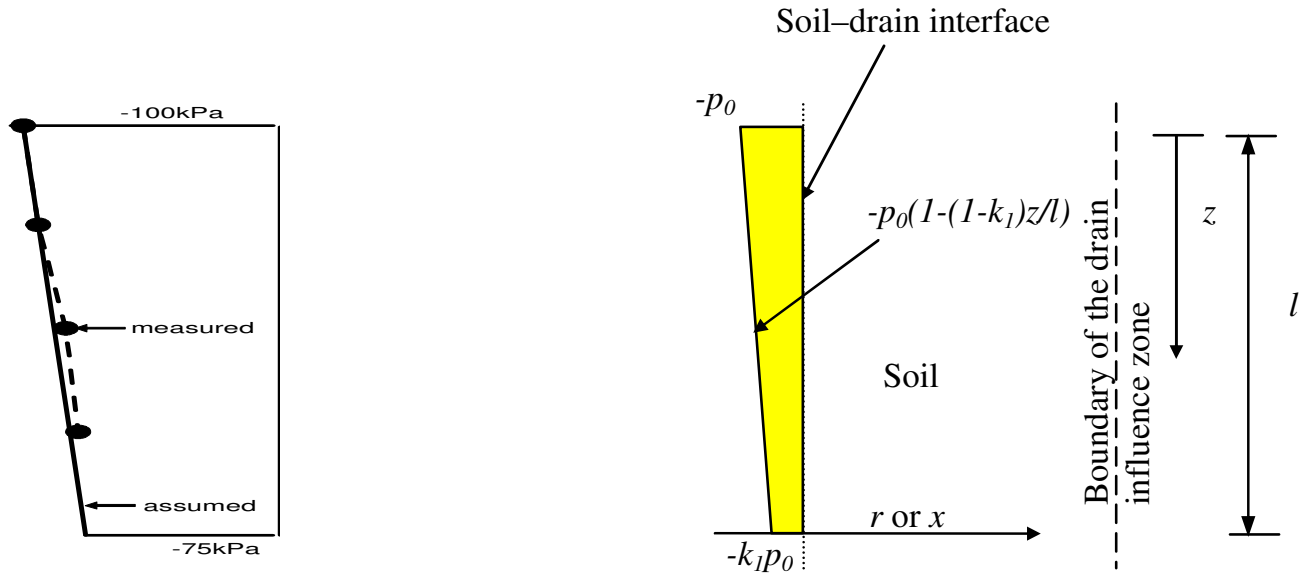

(a)

(b)

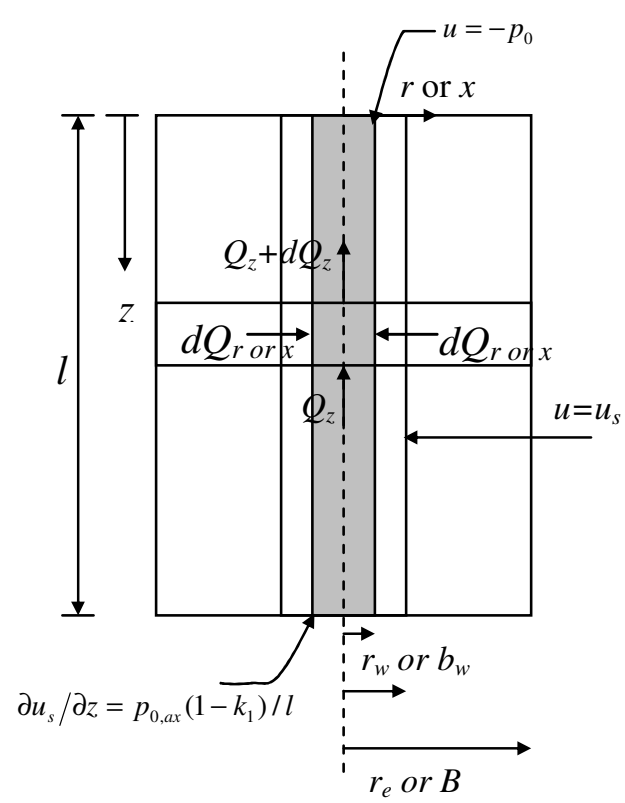

(c)

Figure 2. (a) Distributions of measured negative pore water pressure along drain boundary in laboratory testing, (b) Distributions of vacuum pressure in analytical model, (c) Vertical cross section of unit cell showing flow condition in vertical drain. 


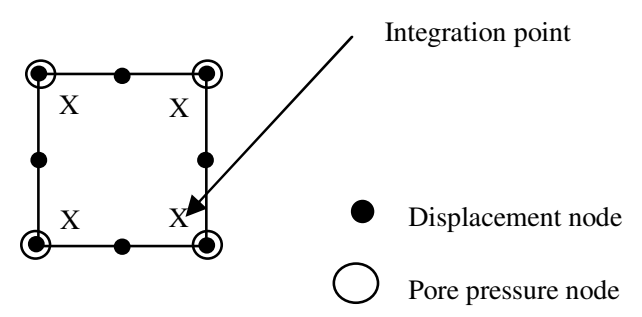

(a)

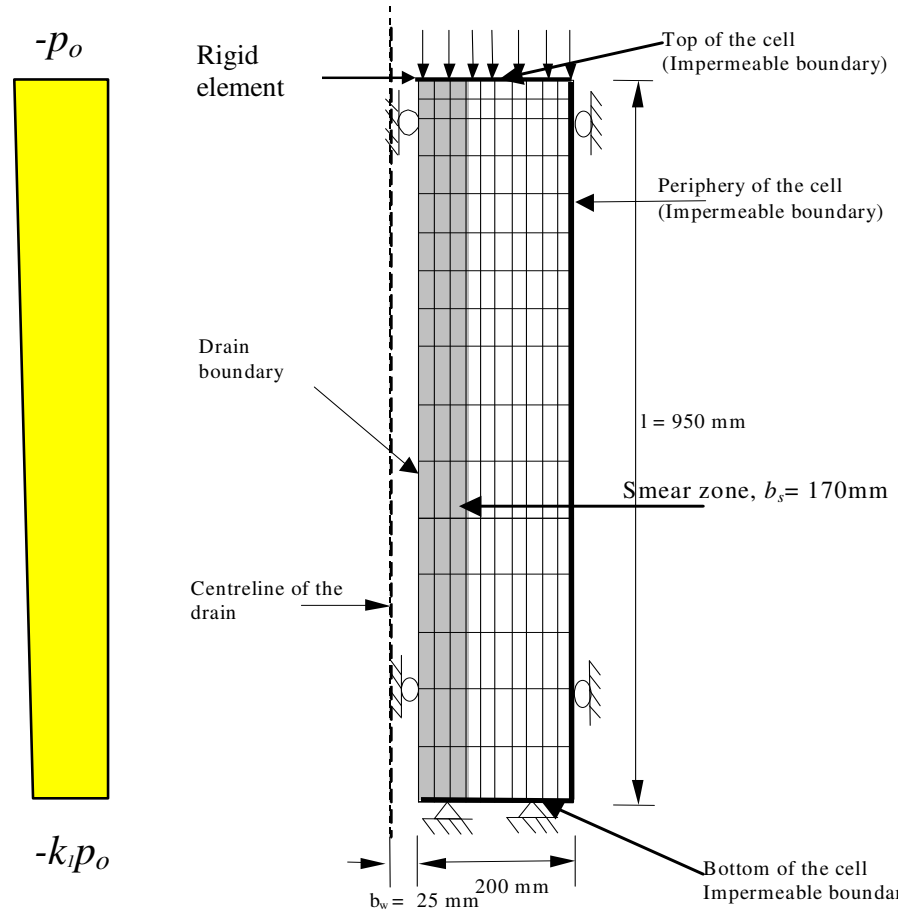

(b) Short drain-Case A

Note: Figures 3(b) and 3(c) are not to scale

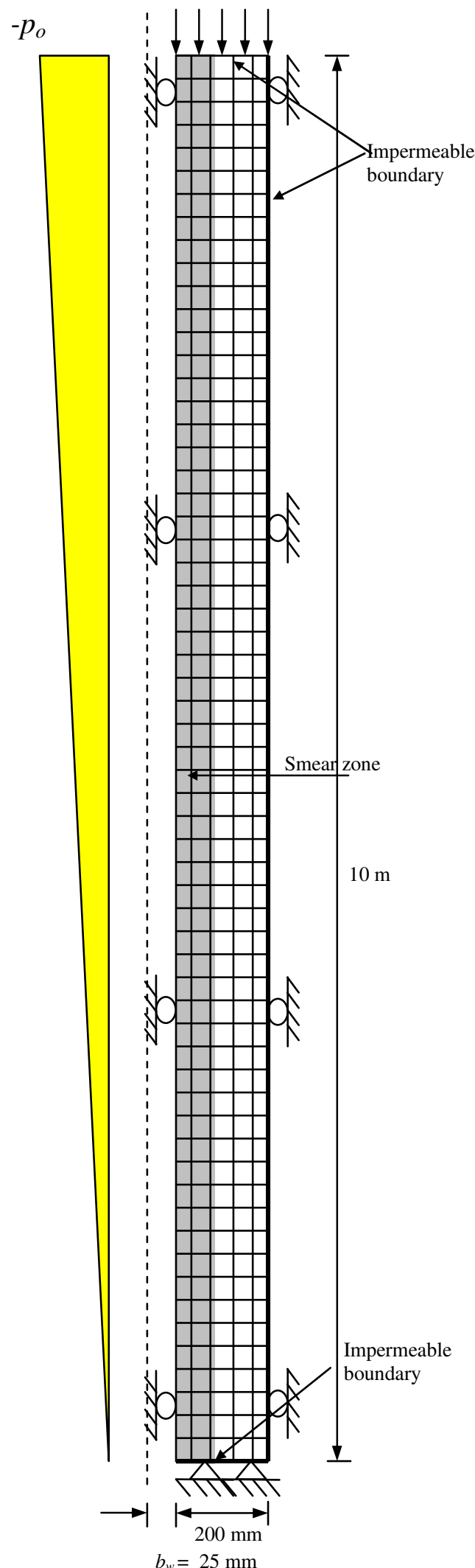

(c) Long drain-Case B

Figure 3. Finite element discretization for axisymmetric and plane strain analyses of soil in unit cell, (a) Nodes and integration points for a single 8-node biquadratic displacement, bilinear pore pressure element; (b) Mesh discretization and vacuum pressure distribution for short drain analysis (Case A), (c) mesh discretization and vacuum pressure distribution for long drain analysis (Case B) 


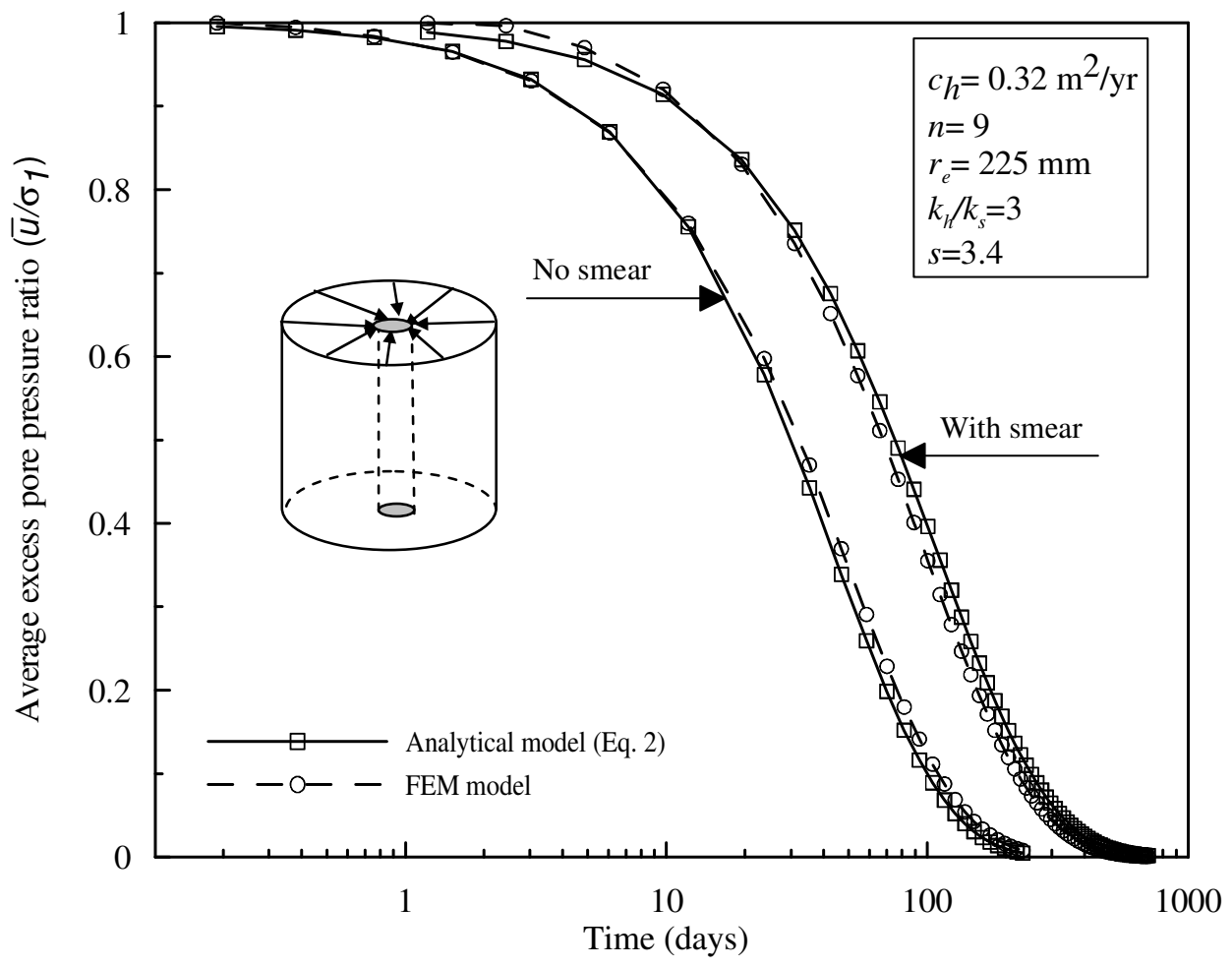

Figure 4. Finite element and analytical model results for axisymmetric condition. 


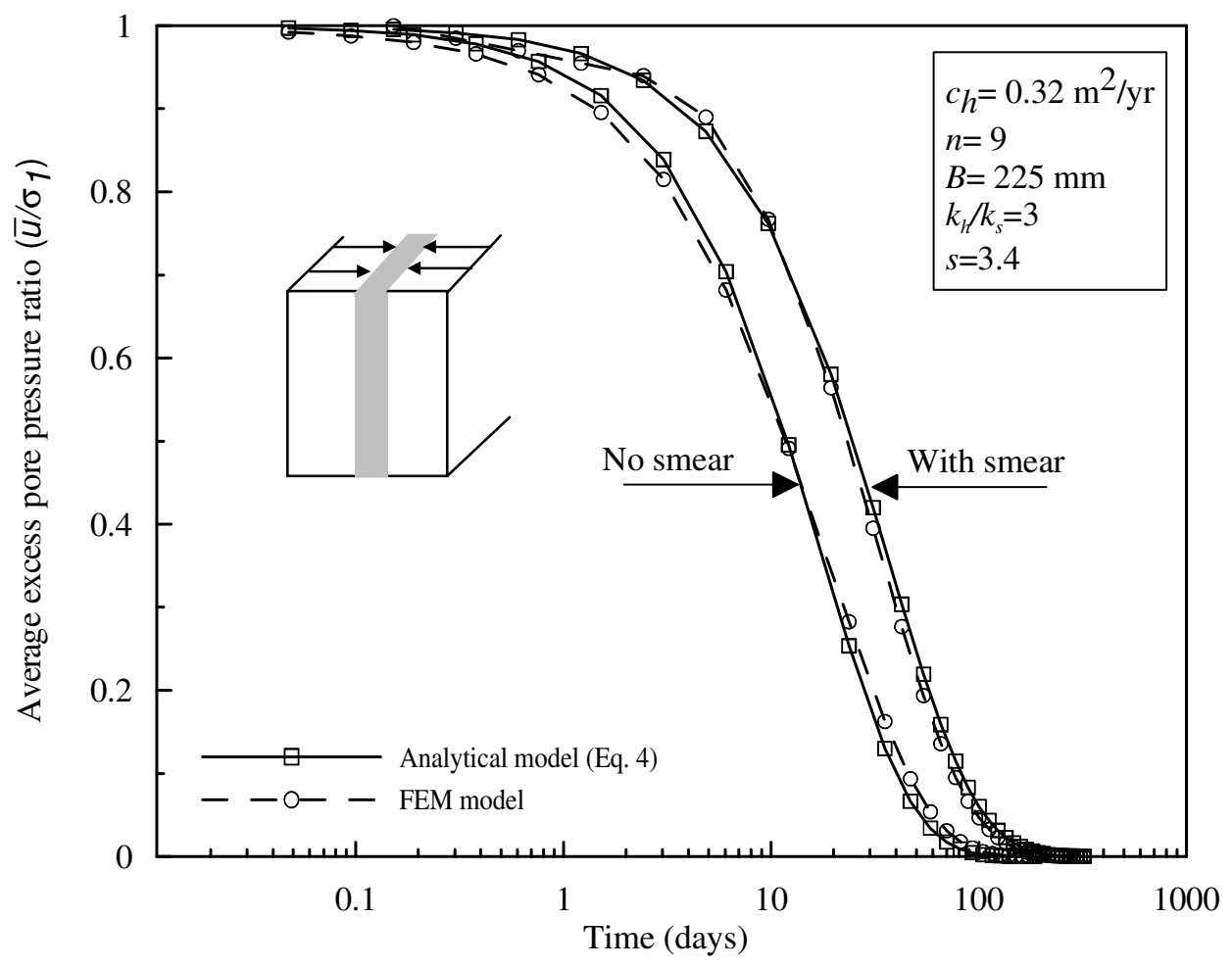

Figure 5. Finite element and analytical model results for plane strain condition. 


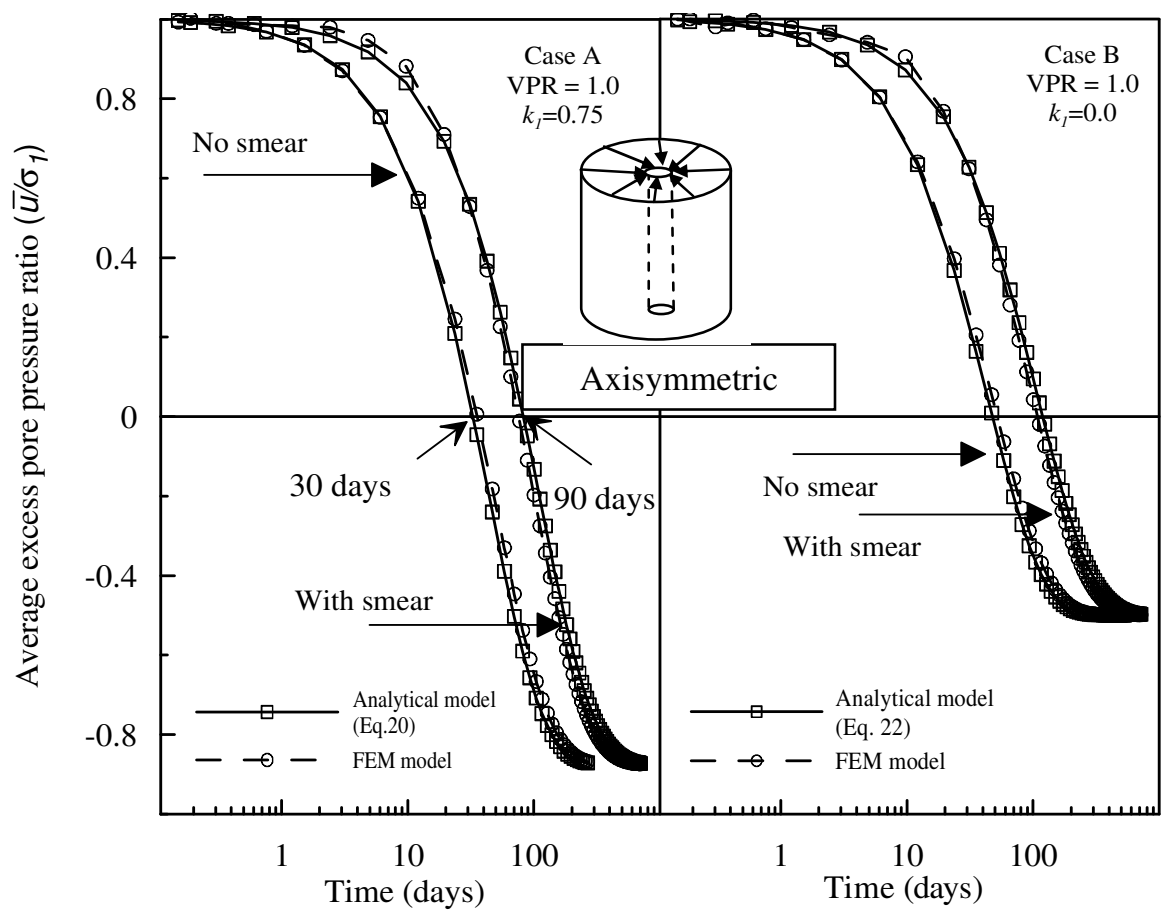

(a)

(b)

Figure 6. Finite element and analytical model results (axisymmetric with vacuum preloading), (a) Case A: short drain analysis, (b) Case B: long drain analysis. 


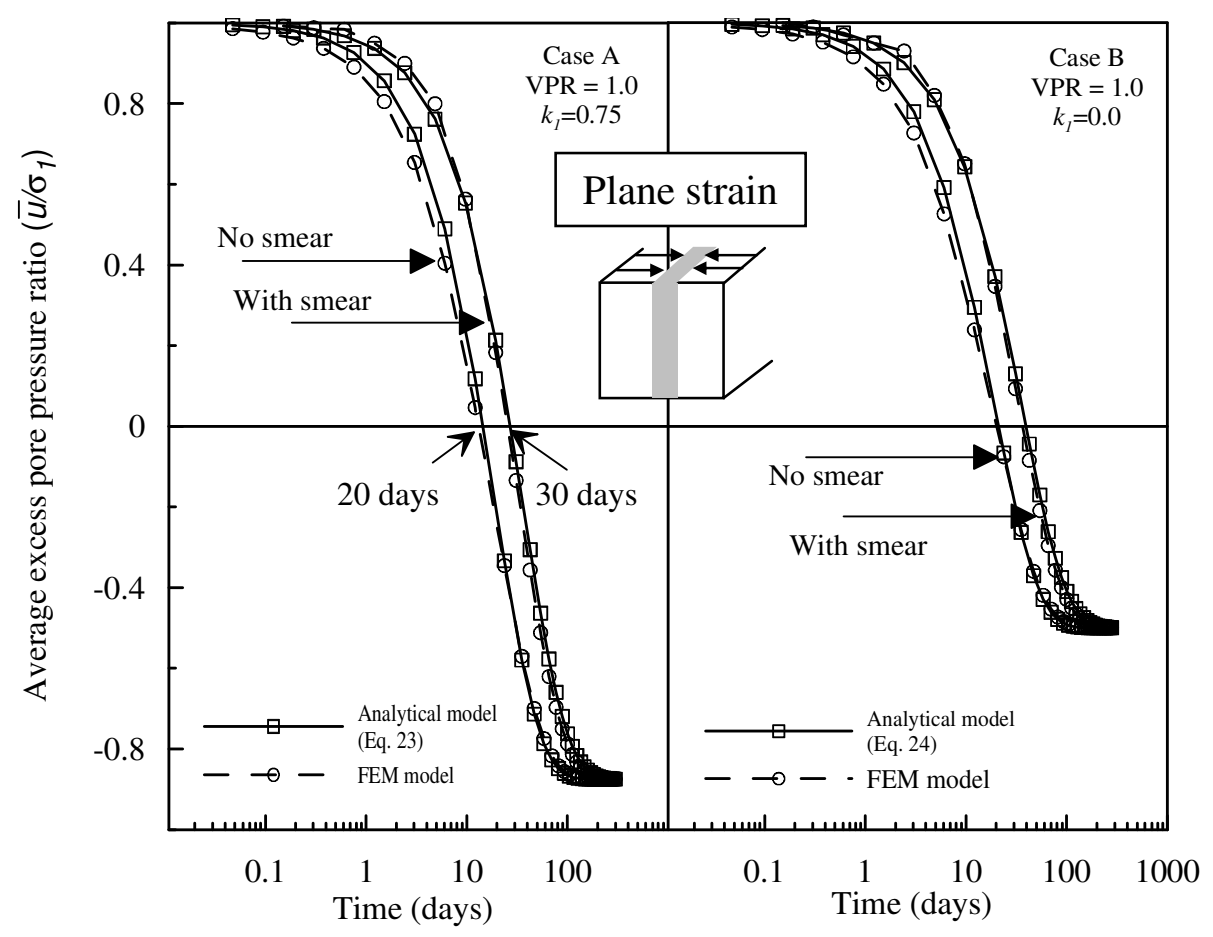

(a)

(b)

Figure 7. Finite element and analytical model results (plane strain with vacuum preloading), (a) Case A: short drain analysis, (b) Case B: long drain analysis. 


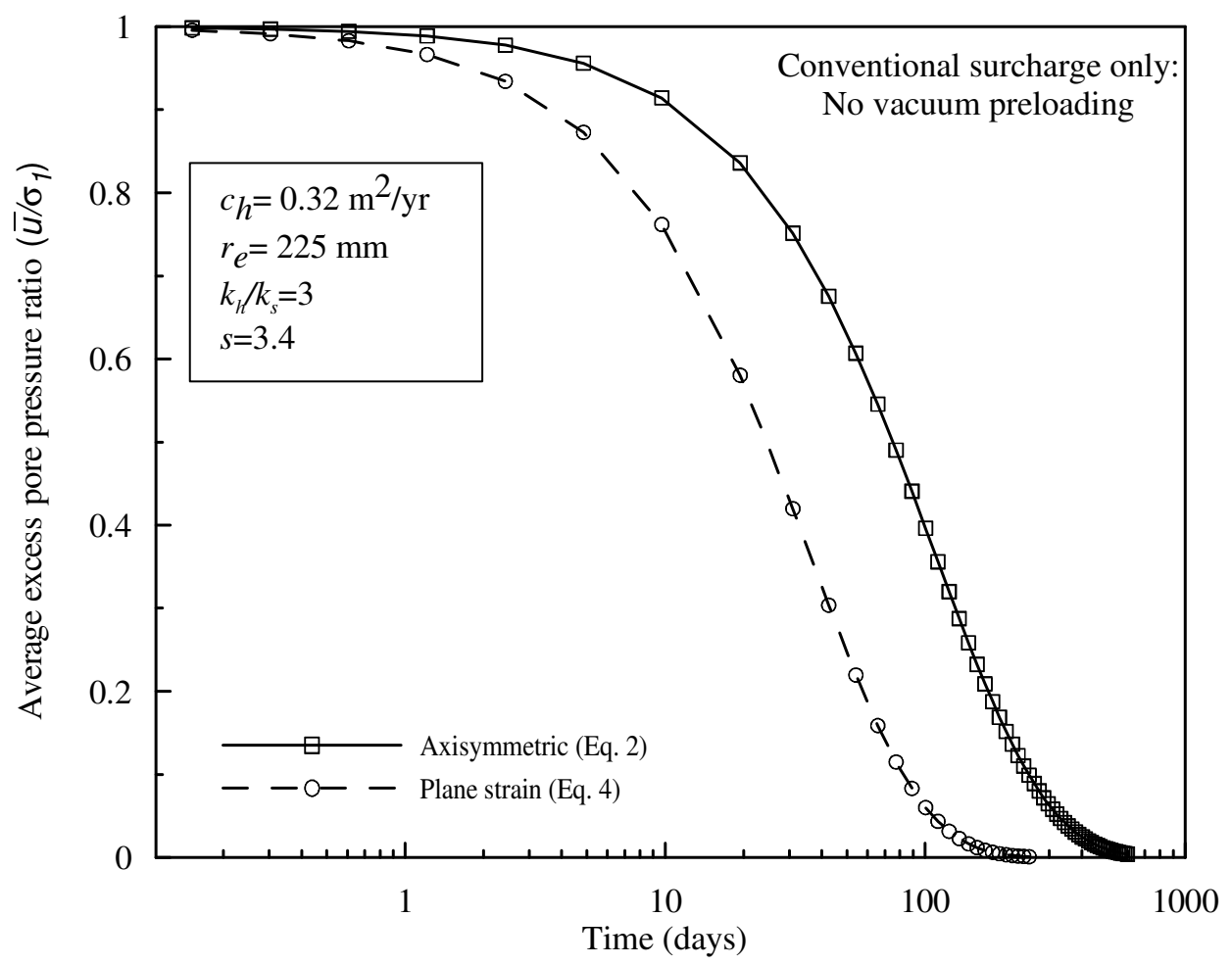

Figure 8. Difference between original axisymmetric and plane strain analyses prior to establishing the equivalent plane strain conversion with smear effect. 


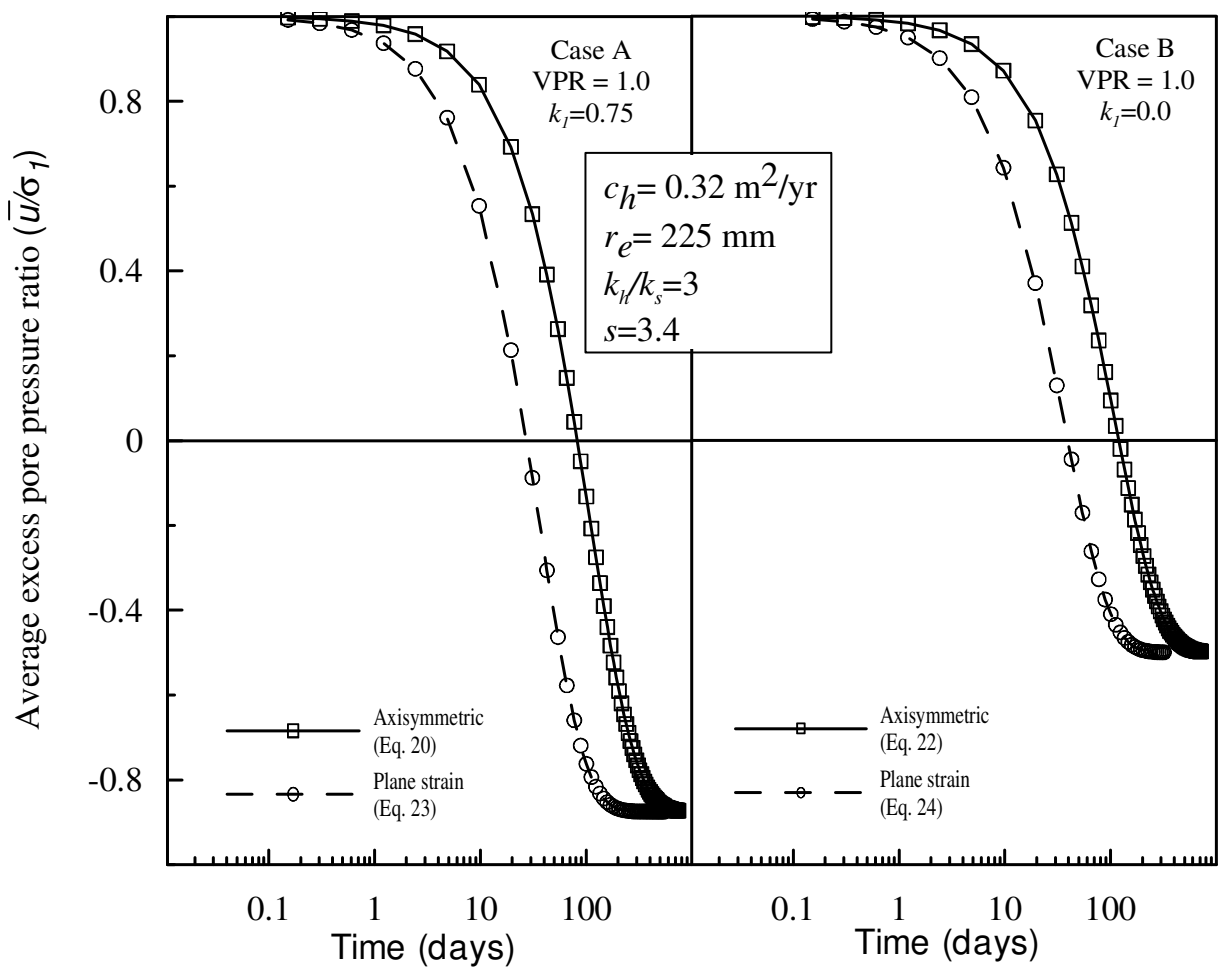

(a)

(b)

Figure 9. Difference between axisymmetric and plane strain analyses prior to establishing the equivalent plane strain conversion, (a) Case A: short drain, (b) Case B: long drain. 


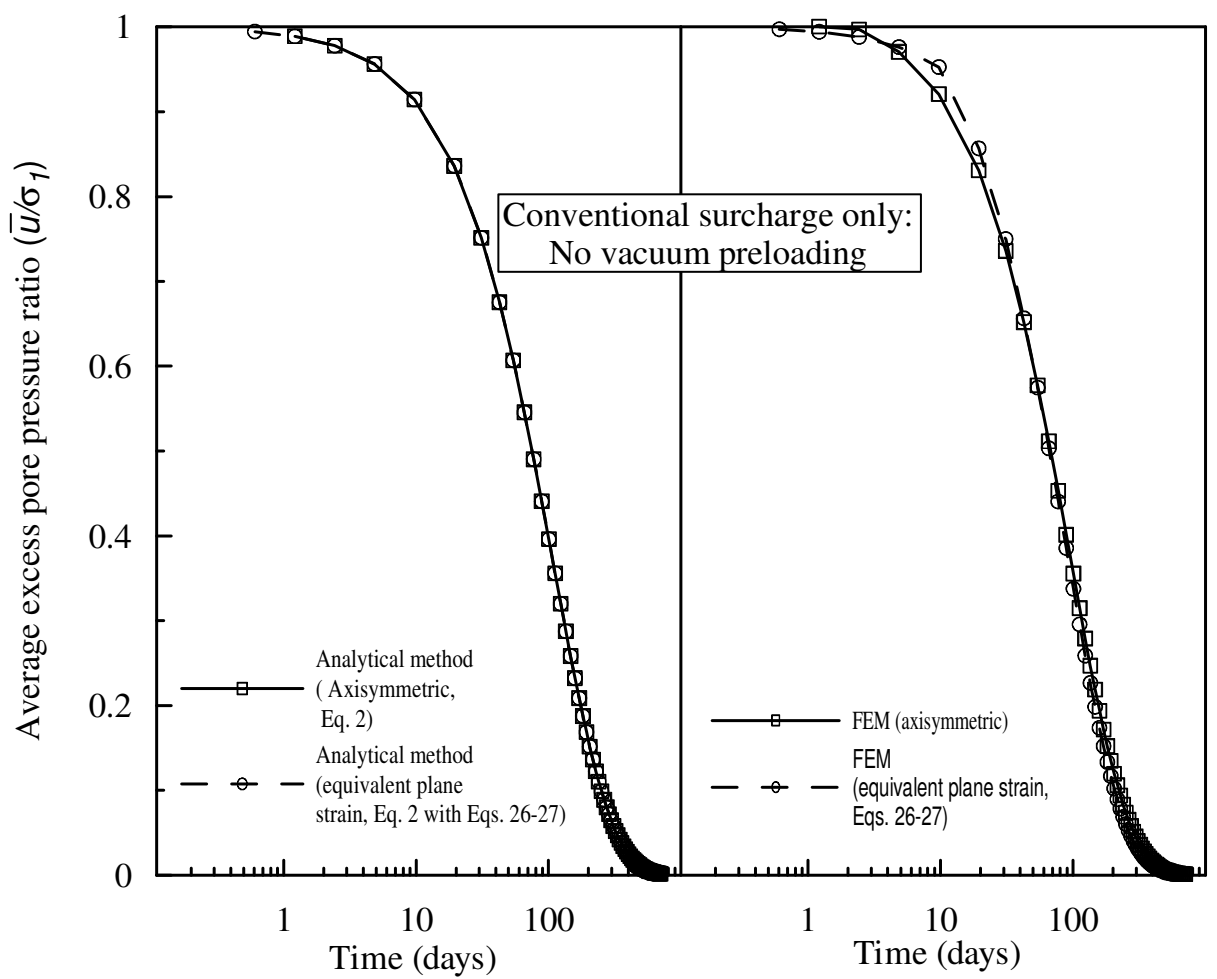

(a)

(b)

Figure 10. Comparison of axisymmetric model with the equivalent plane strain model including smear effect (a) analytical method, (b) FEM. 


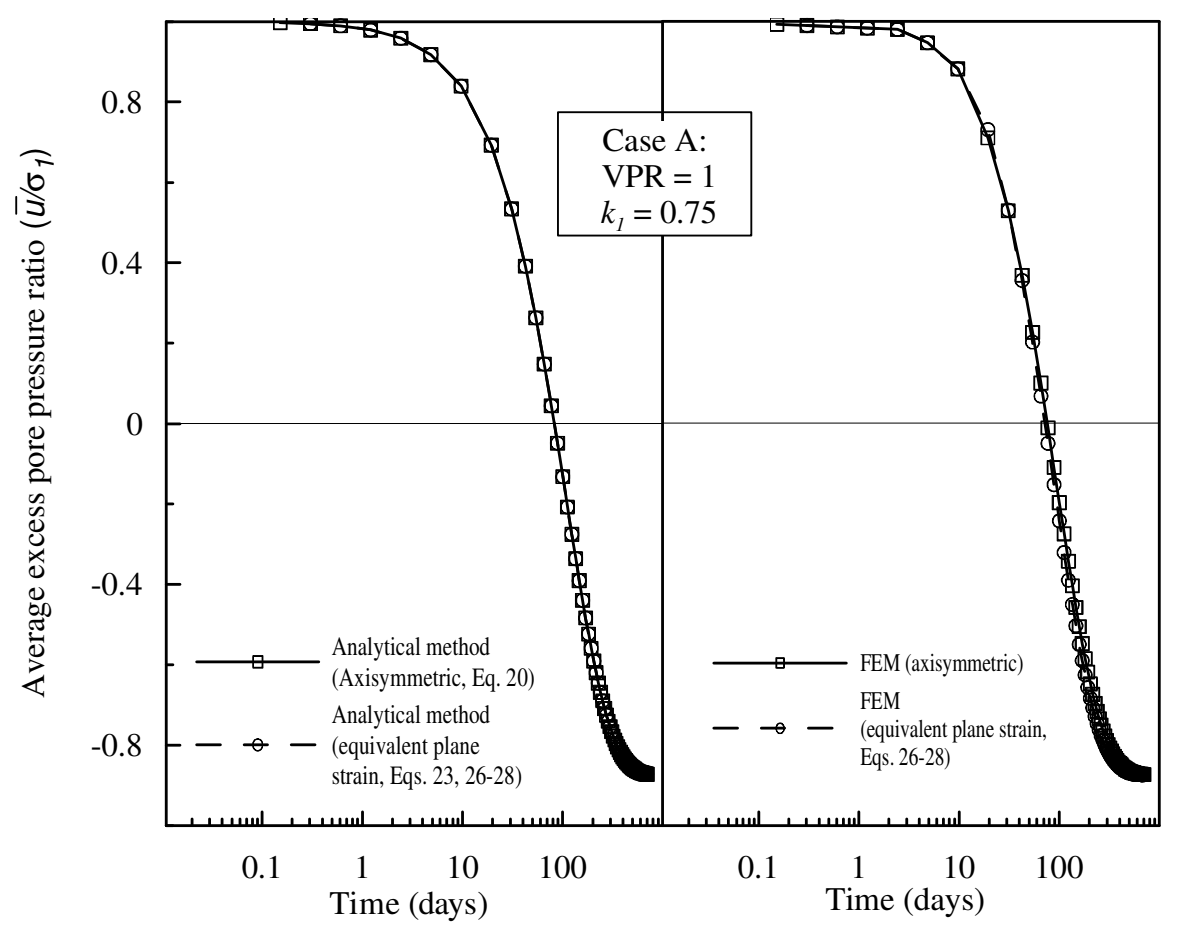

(a)

(b)

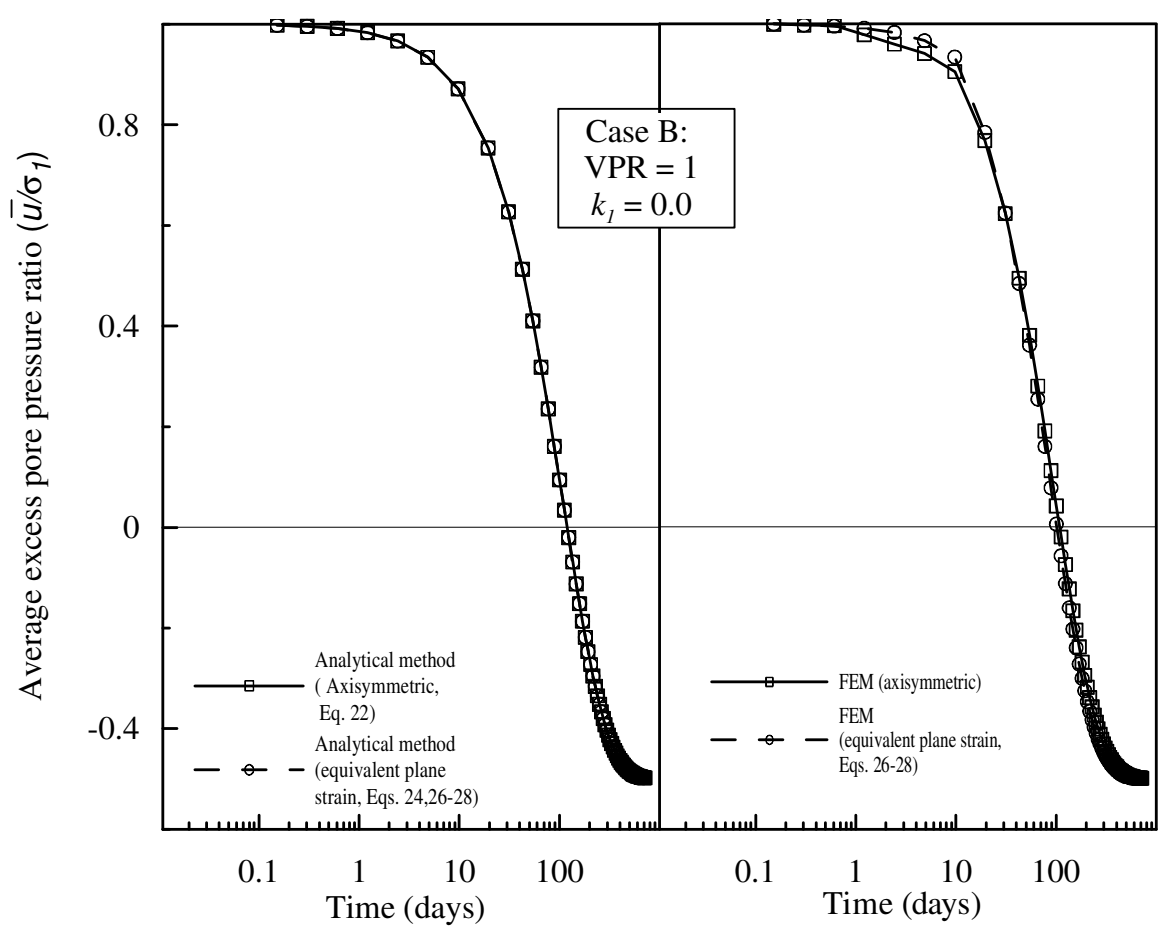

(c)

(d)

Figure 11. Comparison of analytical and FEM solutions after conversion to equivalent plane strain condition including smear effect, (a) Case A, analytical method, (b) Case A, FEM; (c) Case B, analytical method; (d) Case B, FEM. 


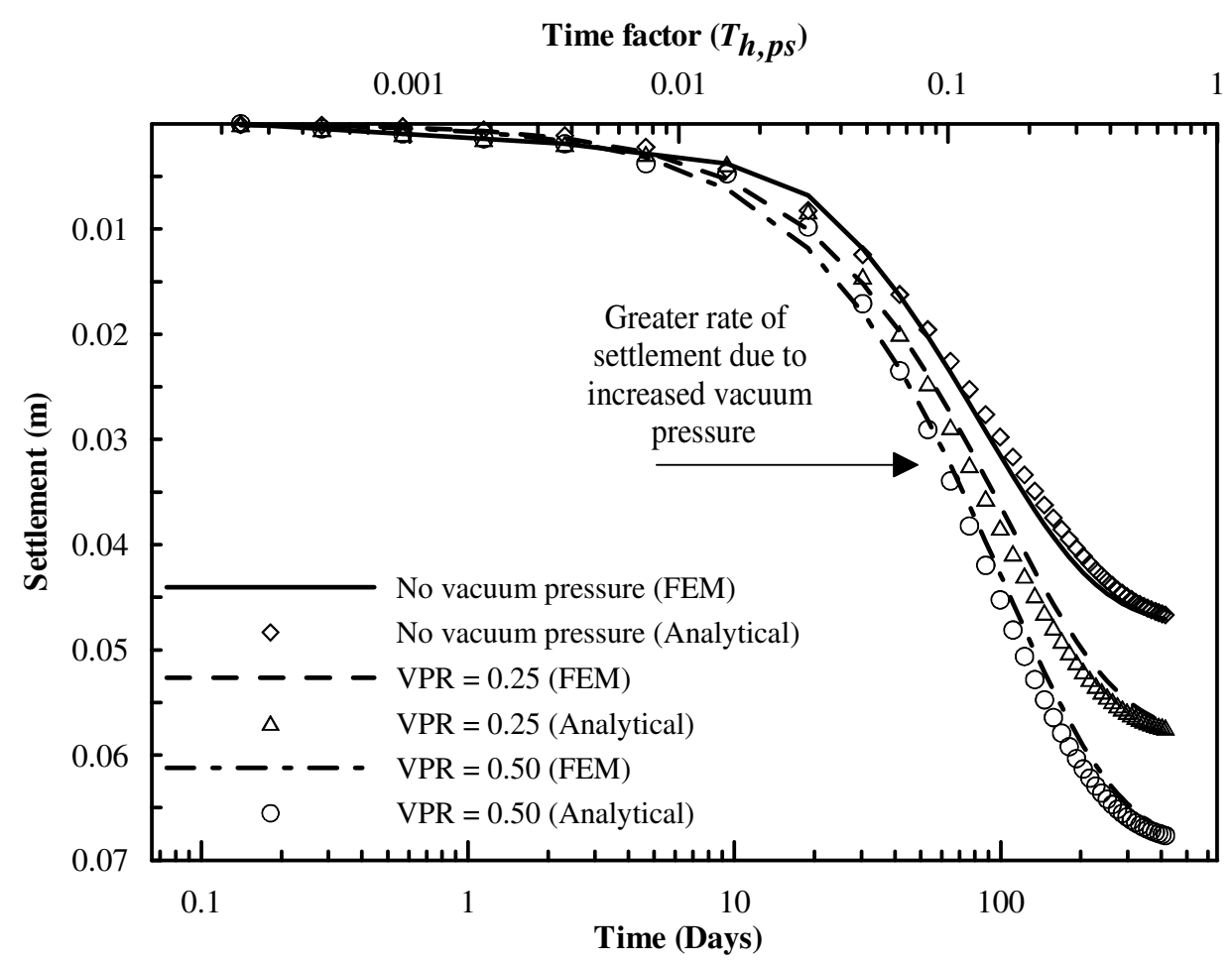

(a)

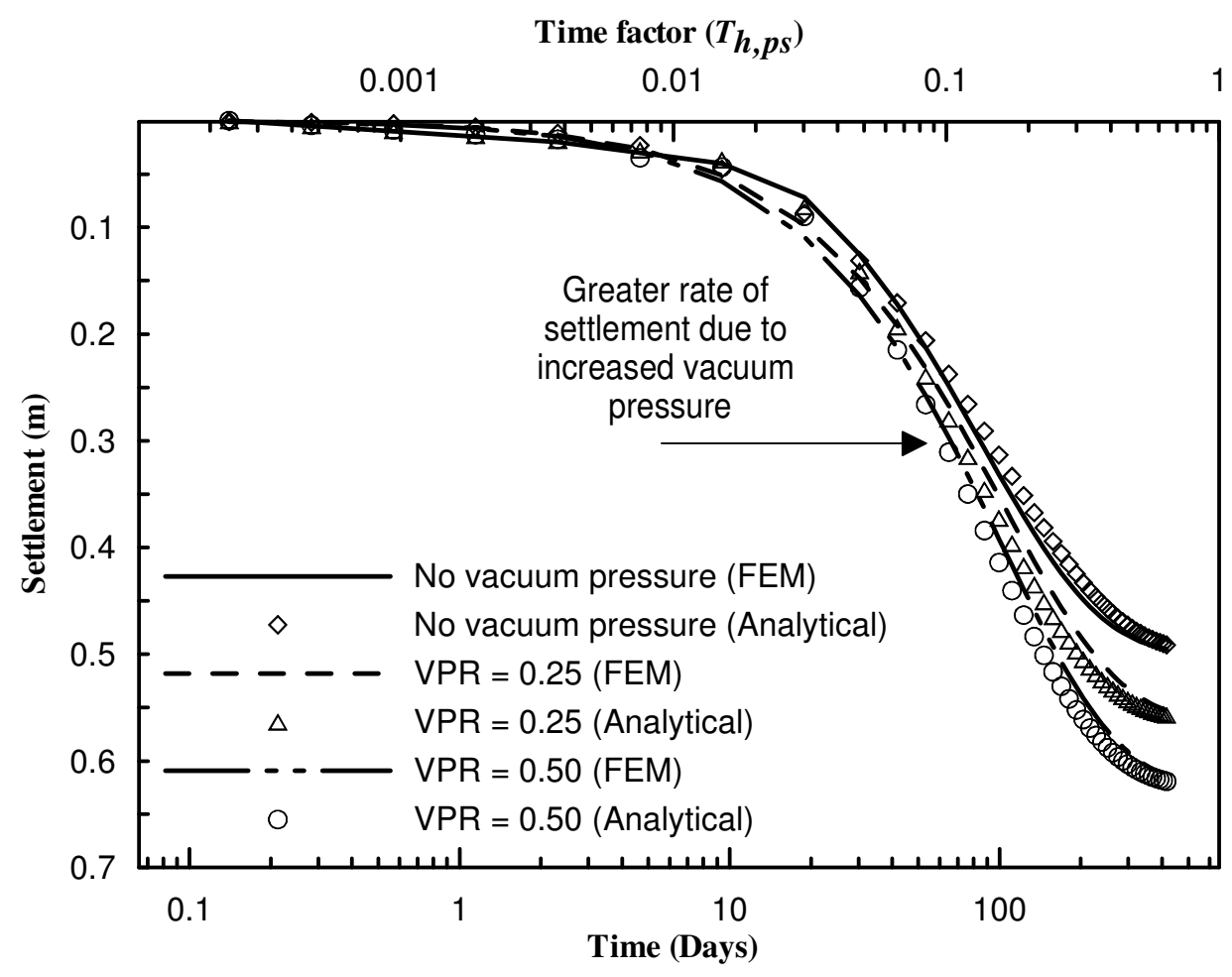

(b)

Figure 12. Settlement results from analytical and FEM solutions after conversion to equivalent plane strain condition, (a) Case A, short drain, (b) Case B, long drain. 


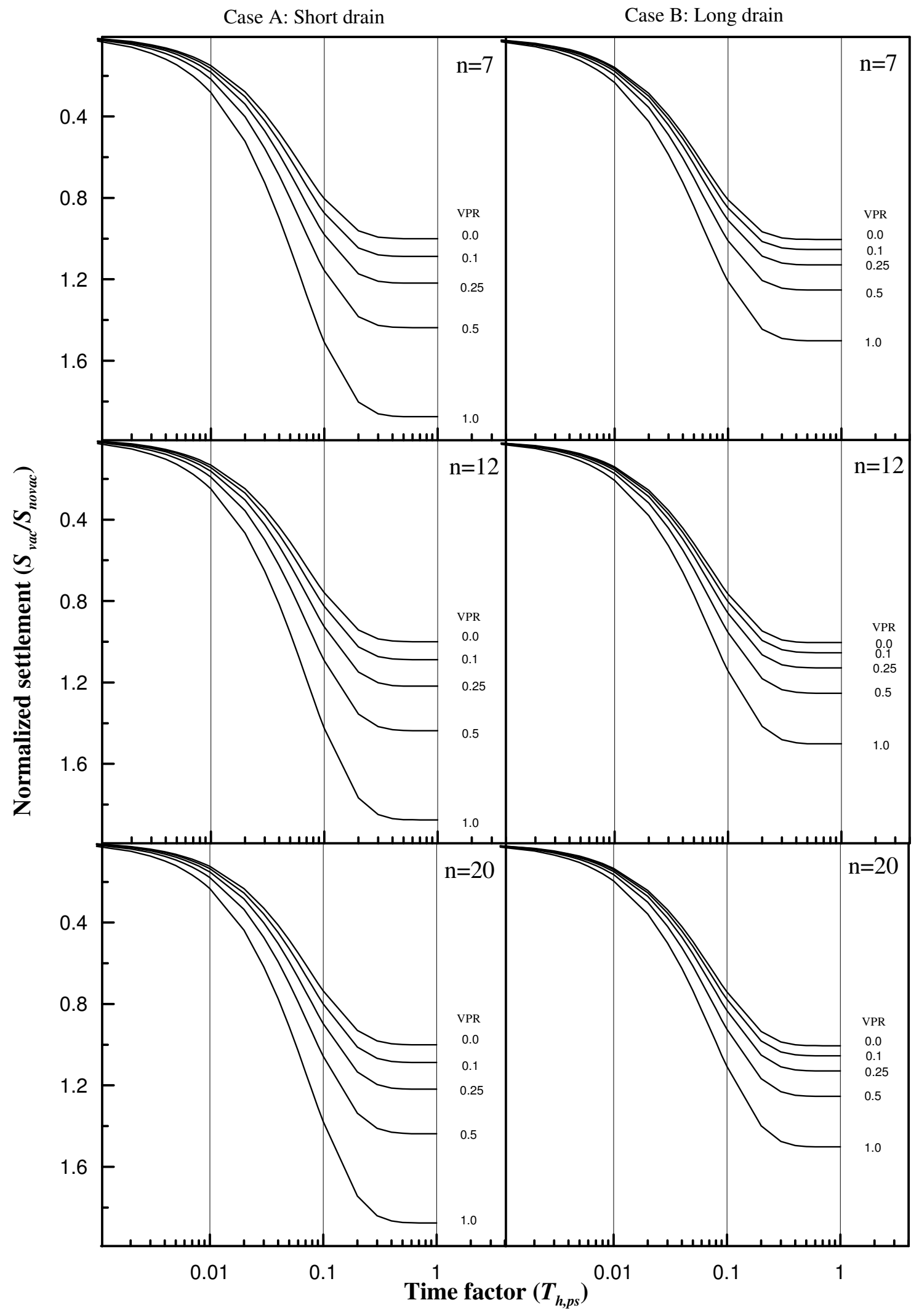

Figure 13. Normalized settlement-time factor curves for varying $n$ and VPR values based on the equivalent plane strain solution for ideal condition. 


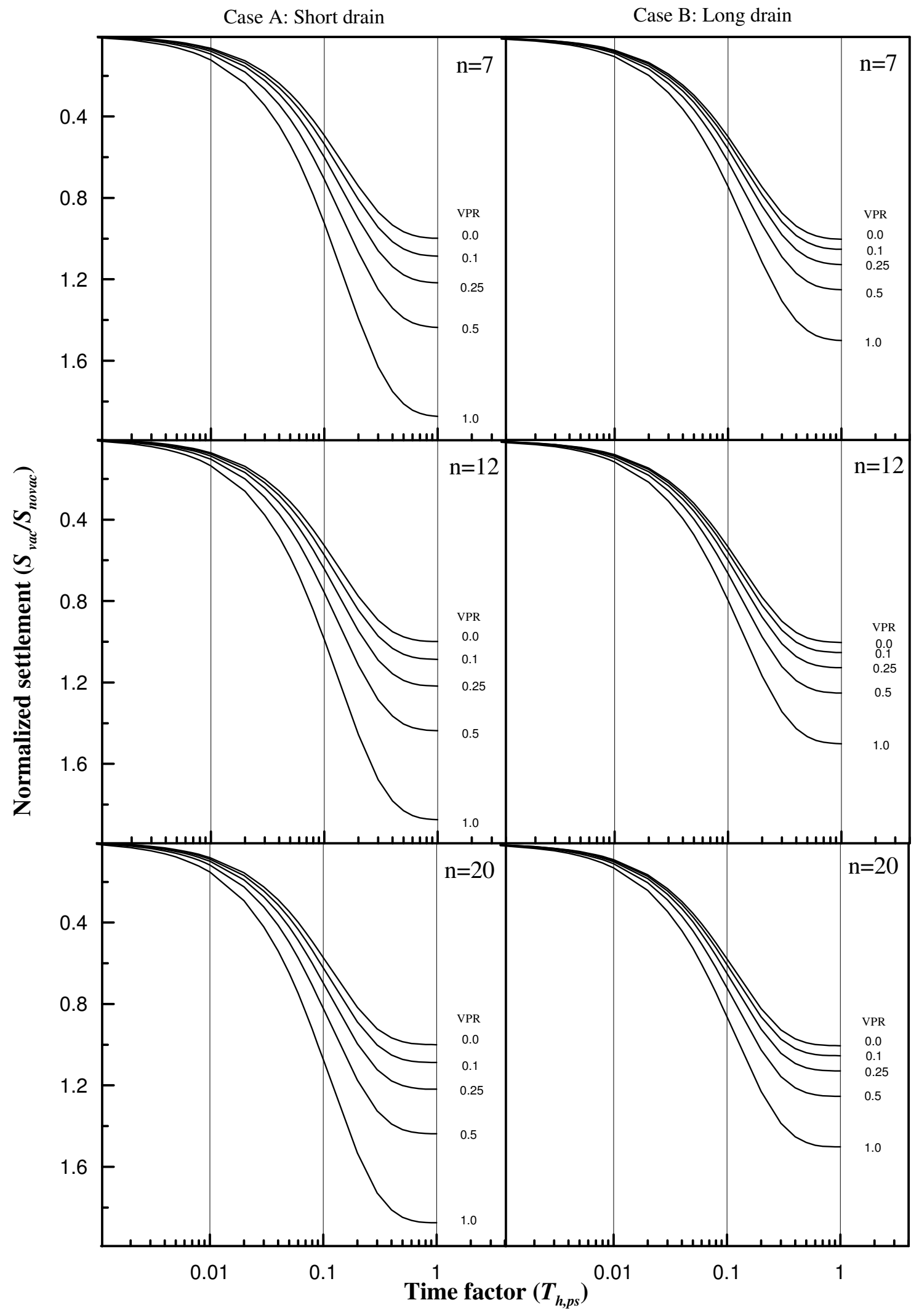

Figure 14. Normalized settlement-time factor curves for varying $n$ and VPR values based on the equivalent plane strain solution for $s=3 k_{h} / k_{s}=3$. 


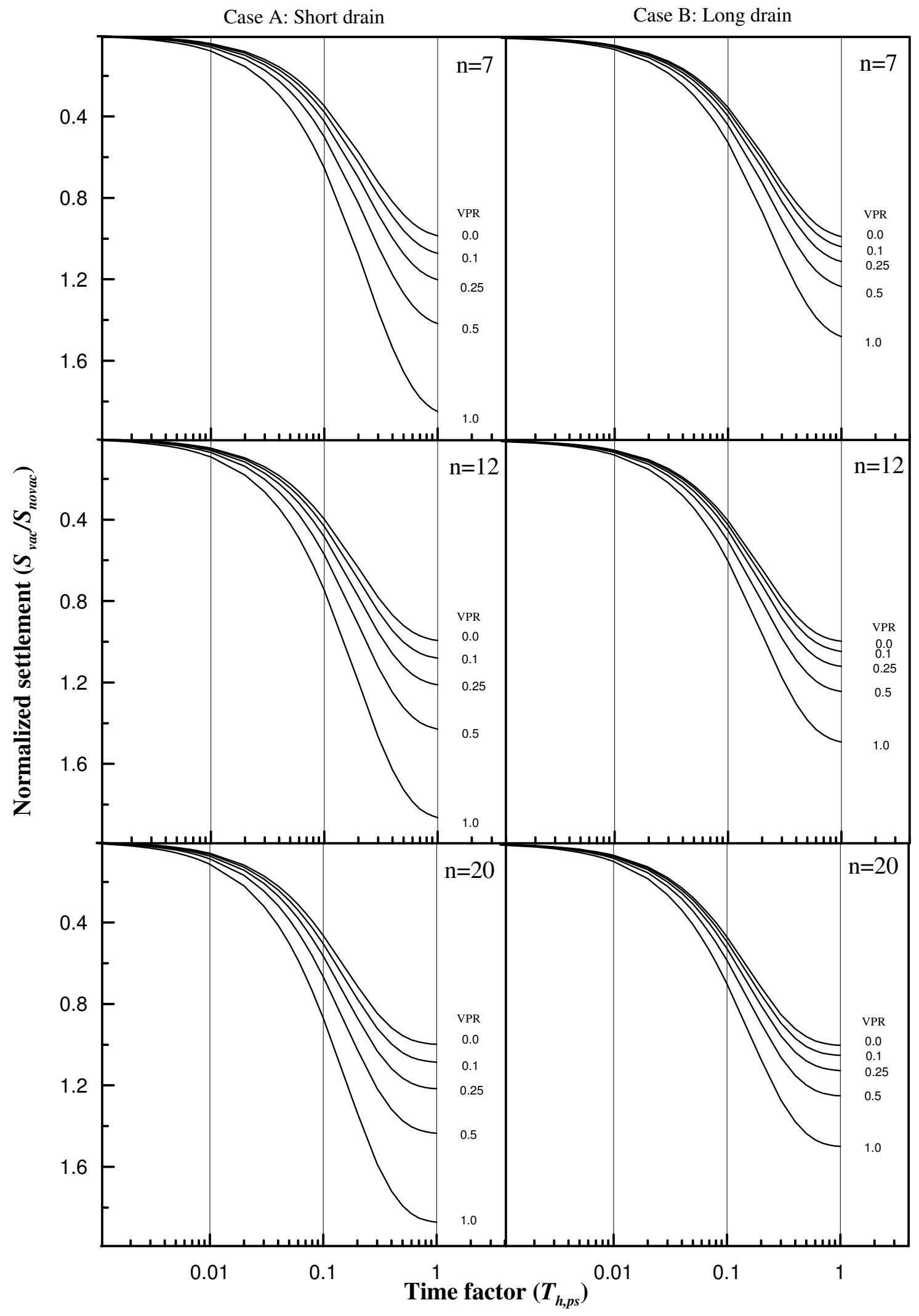

Figure 15. Normalized settlement-time factor curves for varying $n$ and VPR values based on the equivalent plane strain solution for $s=3 k_{h} / k_{s}=5$. 